\title{
Perovskite-Type $\mathrm{CuNbO}_{3}$ Exhibiting Unusual Noncollinear Ferrielectric to Collinear Ferroelectric Dipole Order Transition
}

\author{
Masayuki Fukuda, ${ }^{\dagger}$ Ikuya Yamada, ${ }^{\ddagger}$ Hidenobu Murata, ${ }^{\ddagger}$ Hajime Hojo, ${ }^{\S}$ Olivier J. Hernandez,"l Clemens \\ Ritter, ${ }^{\perp}$ Katsuhisa Tanaka, ${ }^{\dagger}$ and Koji Fujita ${ }^{*}+$
}

${ }^{\dagger}$ Department of Material Chemistry, Graduate School of Engineering, Kyoto University, Katsura, Nishikyo-ku, Kyoto 615-8510, Japan

‡Department of Materials Science, Graduate School of Engineering, Osaka Prefecture University, 1-1 Gakuen-cho, Nakaku, Sakai, Osaka 599-8531, Japan

§Department of Advanced Materials Science and Engineering, Faculty of Engineering Sciences, Kyushu University, 6-1 Kasuga-koen, Kasuga, Fukuoka 816-8580, Japan

'Univ Rennes, CNRS, ISCR (Institut des Sciences Chimiques de Rennes) - UMR 6226, F-35000 Rennes, France

${ }^{\perp}$ Institut Laue-Langevin, 71 avenue des Martyrs, Grenoble 38000, France

ABSTRACT: We report a perovskite oxide with a new type of polar structure, $\mathrm{CuNbO}_{3}$, thanks to the use of high-pressure and high-temperature synthesis. The perovskite-type $\mathrm{CuNbO}_{3}$ was previously obtained under high-pressure and hightemperature conditions, but its crystal structure has not been solved yet. Our structural analysis reveals that $\mathrm{CuNbO}_{3}$ perovskite crystallizes in a polar monoclinic space group (Pc) with a $\sqrt{2} a_{\mathrm{pc}} \times \sqrt{2} a_{\mathrm{pc}} \times 2 a_{\mathrm{pc}}$ unit cell ( $a_{\mathrm{pc}}$ being the pseudo-cubic lattice parameter), which is one maximal non-isomorphic subgroup of the polar rhombohedral space group $R 3 c$. This compound exhibits a remarkable "noncollinear ferrielectric" structure, due to parallel displacements of $\mathrm{Cu}^{+}$and antiparallel displacements of $\mathrm{Nb}^{5+}$ along different axes, representing a new type of polar phase in the perovskite structure. We also observe that the noncollinear ferrielectric $P c$ structure transforms around $470 \mathrm{~K}$ into the collinear ferroelectric $R 3 c$ structure that features parallel displacements of $\mathrm{Cu}^{+}$and $\mathrm{Nb}^{5+}$ in the same direction. The present work extends the accessible composition range of the perovskite niobate series and demonstrates the role of $A-0$ covalency in determining their crystal structure.

\section{INTRODUCTION}

Perovskite niobates, $A \mathrm{Nb}^{5+} \mathrm{O}_{3}(A=\mathrm{Li}, \mathrm{Na}, \mathrm{K}$, and $\mathrm{Ag})$, constitute an important class of oxide materials, exhibiting a wide range of properties including piezoelectricity, ferroelectricity, antiferroelectricity, and electro-optical and nonlinear optical effects. ${ }^{1-4}$ Recently, they also have attracted much attention due to their excellent photocatalytic and photovoltaic properties. ${ }^{5-7}$

The lattice instabilities and structural distortions of perovskite oxides are often discussed in terms of the tolerance factor, $t=R_{\mathrm{A}-0} / \sqrt{2}\left(R_{\mathrm{B}-0}\right)$, where $R_{\mathrm{A}-0}$ and $R_{\mathrm{B}-0}$ are the ideal $A-O$ and $B-O$ bond lengths for a particular $A B O_{3}$ material, respectively, calculated using the bond valence model ${ }^{8}$. For example, $\mathrm{KNbO}_{3}$ is ferroelectric with $t>1(t=$ 1.06), displaying so-called $B$-site driven ferroelectricity. ${ }^{9-11}$ The $B$-site cation (i.e., $\mathrm{Nb}^{5+}$ ) is nominally too small for its octahedral site and can off center. In the room-temperature phase of $\mathrm{KNbO}_{3}$, second-order Jahn-Teller distortions ${ }^{12-14}$ for $\mathrm{Nb}^{5+}\left(4 \mathrm{~d}^{0}\right)$ ions yield their off-center displacements along the pseudo-cubic $\langle 110\rangle_{\mathrm{pc}}$ axis, leading to an orthorhombic ferroelectric structure (space group Amm2). Conversely, $\mathrm{LiNbO}_{3}$ is ferroelectric with $t<1(t=0.85)$, exhibiting $A$-site driven ferroelectricity. ${ }^{15,16}$ It can be described by a grossly distorted perovskite-type structure. Generally, perovskites with $t<1$ are not ferroelectric at all, and instead find favorable bond lengths through tilts of $\mathrm{BO}_{6}$ octahedra about various axes, which preserve the inversion symmetry. The notable exceptions, including $\mathrm{LiNbO}_{3}$, are perovskites with very small $t$ values, where a combination of the out-of-phase tilts of $\mathrm{BO}_{6}$ octahedra around the [111] $]_{\mathrm{pc}}$ axis $\left(a^{-} a^{-} a^{-}\right.$tilt system in Glazer notation ${ }^{17}$ ) and polar displacements of $A$ site cations along the same axis yield a rhombohedral ferroelectric structure (space group $R 3 c$ ).

Since the $t$ values of $\mathrm{NaNbO}_{3}(t=0.97)$ and $\mathrm{AgNbO}_{3}(t=$ 0.97 ) are slightly less than 1 , the coexistence of off-center $\mathrm{Nb}$ displacements and $\mathrm{NbO}_{6}$ octahedral tilts provides complex crystal structures and phase diagrams. ${ }^{19-26}$ The room-temperature phase of $\mathrm{NaNbO}_{3}$ is characterized by a sequence of two octahedral tilts system $\left(a^{-} a^{-} c^{+} / a^{-} a^{-} c^{-}\right)$, and adopts an orthorhombic antiferroelectric structure (space group $\mathrm{Pbcm}$ ), where the displacements of $\mathrm{Nb}^{5+}$ ions as well as of $\mathrm{Na}^{+}$ions are ordered in an antiferroelectric way and thereby the respective dipole moments are cancelled within the unit cell. ${ }^{18,22}$ Despite the similar ionic radii (twelvecoordinated) of $\mathrm{Ag}^{+}\left(1.37 \AA\right.$ ) and $\mathrm{Na}^{+}$(1.39 ̊), $\operatorname{AgNbO}_{3}$ crystallizes in a different structure from $\mathrm{NaNbO}_{3}$. Recent 
studies have revealed that $\mathrm{AgNbO}_{3}$ is ferroelectric at room temperature, forming an orthorhombic ferroelectric structure (space group $\left.P m c 2_{1}\right)^{26}$ The $\mathrm{Pmc}_{1} \mathrm{AgNbO}_{3}$ exhibits the same octahedral tilts system as the $\mathrm{Pbcm}$ $\mathrm{NaNbO}_{3}$, but their cation displacements are ordered in a different way. In the case of $\mathrm{AgNbO}_{3}$, both displacements of $\mathrm{Ag}^{+}$and $\mathrm{Nb}^{5+}$ ions are ordered in a ferrielectric way, and thus the respective dipole moments are not completely cancelled within the unit cell. The uncompensated ionic displacements lead to a net polarization and weak ferroelectricity. ${ }^{25,}{ }^{26}$ Here, it should be noted that the ordered dipole moments from the displacements of $\mathrm{Ag}^{+}$and $\mathrm{Nb}^{5+}$ ions are collinear to the $\langle 100\rangle_{\mathrm{pc}}$ axis. Namely, $\mathrm{AgNbO}_{3}$ adopts a collinear ferrielectric structure. Yashima and Matsuyama pointed out that the formation of ferrielectric structure is ascribed to covalency of $\mathrm{Ag}-\mathrm{O}$ bonds as well as of $\mathrm{Nb}-\mathrm{O}$ bonds; the covalent character arises from the $\mathrm{Ag}$ $4 \mathrm{~d}-\mathrm{O} 2 \mathrm{p}$ and $\mathrm{Nb} 4 \mathrm{~d}-\mathrm{O} 2 \mathrm{p}$ orbital overlaps. ${ }^{27} \mathrm{The} \mathrm{Ag}-\mathrm{O}$ and $\mathrm{Nb}-\mathrm{O}$ covalencies are also responsible for visible photocatalytic properties of $\mathrm{AgNbO}_{3}$.

Given the versatility and functionality of perovskite niobates, it is interesting to extend their compositional space to other systems. In this study, $\mathrm{Cu}^{+}$-based perovskite niobate, $\mathrm{CuNbO}_{3}$, is targeted because of the expectation that as in the case of $\mathrm{AgNbO}_{3}$, the covalent $A-0$ and $B-0$ bonding due to $\mathrm{Cu} 3 \mathrm{~d}-\mathrm{O} 2 \mathrm{p}$ and $\mathrm{Nb} 4 \mathrm{~d}-\mathrm{O} 2 \mathrm{p}$ orbital overlaps would result in an unusual electric dipole order. However, although $A \mathrm{NbO}_{3}(A=\mathrm{Li}, \mathrm{Na}, \mathrm{K}$, and $\mathrm{Ag})$ can be synthesized under ambient conditions, $\mathrm{CuNbO}_{3}$ crystallizes in a nonperovskite structure in such conditions; the ambientpressure phase of $\mathrm{CuNbO}_{3}\left(\mathrm{AP}-\mathrm{CuNbO}_{3}\right)$ adopts a $\mathrm{RbTaO}_{3}$ type structure with a nonpolar monoclinic $\mathrm{C} 2 / \mathrm{m}$ symmetry. ${ }^{28,29} \mathrm{AP}^{2} \mathrm{CuNbO}_{3}$ is characterized by a corner- and edge-sharing $\mathrm{NbO}_{6}$ lamellar structure, in contrast to the perovskite structure with corner-sharing $\mathrm{NbO}_{6}$ octahedra. Utilizing an ion exchange in $\mathrm{AP}-\mathrm{CuNbO}_{3}$, a new form of $\mathrm{LiNbO}_{3}$ with a lamellar structure was synthesized for the electrochemical applications. ${ }^{30}$ The perovskite instability in $\mathrm{CuNbO}_{3}$ is partly ascribed to the small $\mathrm{Cu}^{+}$ions on the $A$ sites, leading to a small $t$ value ( $t=0.89$ ). We show here that the powerful high-pressure synthesis allows us to isolate a polar $\mathrm{CuNbO}_{3}$ perovskite. The application of high pressure stabilizes phases that are inaccessible metastable products under ambient pressures. In particular, new perovskites and related oxides have emerged through exploration of the high-pressure and high-temperature phases of $\mathrm{ABO}_{3}$ ternary systems. ${ }^{31}, 32$ In 1970, Sleight et al. reported the synthesis of a monoclinic perovskite-type $\mathrm{CuNbO}_{3}$ at 6.5 GPa and 1273-1473 K, but no space group was unambiguously identified. ${ }^{33}$ Clearly, the crystal structure of high-pressure-synthesized $\mathrm{CuNbO}_{3} \quad\left(\mathrm{HP}^{\left.-\mathrm{CuNbO}_{3}\right)}\right.$ has remained elusive so far.

Herein, we present a comprehensive structural characterization of the metastable perovskite phase of HP-
$\mathrm{CuNbO}_{3}$ using X-ray, neutron, and electron diffraction as well as optical second harmonic generation, combined with first-principles lattice dynamics calculations. The results show that $\mathrm{HP}-\mathrm{CuNbO}_{3}$ crystallizes in a monoclinic perovskite-type structure (space group $P c$ ), featuring an unusual electric dipole order that represents a new type of polar phase in the perovskite structure. The perovskitetype $P c$ phase is a weakly polar material due to a "noncollinear ferrielectric" dipole order, i.e., a combination of parallel displacements of $\mathrm{Cu}^{+}$ions along [111] $]_{\mathrm{pc}}$ with respect to the closed-packed oxygen planes and antiparallel displacements of $\mathrm{Nb}^{5+}$ ions along $\langle 100\rangle_{\mathrm{pc}}$ with respect to the octahedral centroids. We also observe that, upon heating to $470 \mathrm{~K}$ in ambient pressure, the weakly polar $P c$ phase transforms into the strongly polar $R 3 c$ phase with parallel displacements of $\mathrm{Cu}^{+}$and $\mathrm{Nb}^{5+}$ ions. Our results highlight that the bonding nature of $A$-site cations, as well as their ionic size, has great impact on electric dipole order in small-tolerance-factor perovskites.

\section{EXPERIMENTAL AND COMPUTATIONAL DETAILS}

Polycrystalline samples of $\mathrm{CuNbO}_{3}$ were prepared by the solid-state reaction at high pressure and high temperature. Stoichiometric amounts of the starting materials, $\mathrm{Cu}_{2} \mathrm{O}$ (99.9\%, Rare Metallic) and $\mathrm{Nb}_{2} \mathrm{O}_{5}$ (99.99\%, Sigma-Aldrich) were ground and mixed carefully. The mixed powder was placed into a Pt capsule and put into a high-pressure cell. The solid-state reaction was performed at $12 \mathrm{GPa}$ and 1273 $\mathrm{K}$ for 30 min with a Walker-type high-pressure apparatus, followed by a rapid temperature quench and then a gradual pressure release.

Electron diffraction (ED) patterns were taken from single-crystal domains at room temperature using a JEMARM200F (JEOL) transmission electron microscope. Synchrotron X-ray diffraction (SXRD) data were recorded at room temperature $(\lambda=0.75003 \AA)$ and in the temperature range of 300 to $680 \mathrm{~K}(\lambda=0.77565 \AA)$ on the BL02B2 beamline at SPring-8. The powder sample was loaded into a Lindemann glass capillary with an inner diameter of $0.1 \mathrm{~mm}$ continuously rotated during the measurement to reduce the effect of preferential orientation. Neutron powder diffraction (NPD) data were collected at room temperature on the D2B instrument at the Institut Laue-Langevin, Grenoble $(\lambda=1.594 \AA$ Å). A 475.7-mg sample was encased in a vanadium can. The crystal structure was refined using the Rietveld analysis programs Fullprof ${ }^{34}$ and JANA2006. ${ }^{35}$ In the former case, a Thompson-Cox-Hastings pseudo-Voigt profile function was used, as well the Berar \& Baldinozzi model for asymmetry correction. Anisotropic broadening was taken into account through spherical harmonics coefficient (size effect) or generalized $S_{H K L}$ strain parameters. The width of few isolated reflections was additionally selectively relaxed. An absorption correction 
was applied for the SXRD refinement. DICVOL06 ${ }^{36}$ was used to index the diffraction pattern. The structure solution was carried out through the direct method with EXP02013. ${ }^{37}$ The crystal structures were drawn using the program VESTA $^{38}$ based on the structural refinement results. The cation ratio within the sample was determined with inductively coupled plasma optical emission spectroscopy (ICP-OES) on a SPECTROBLUE (SPECTRO).

To investigate the presence of noncentrosymmetry, a second-harmonic generation (SHG) response was measured at room temperature using a pulsed Nd:YAG laser $(\lambda, 1064 \mathrm{~nm}$; pulse duration, $25 \mathrm{ps}$; repetition frequency, 10 $\mathrm{Hz}$ ) as the light source. The SHG light from the sample was detected with a photomultiplier tube through a 532-nm narrow band-pass filter. X-ray absorption near edge structure (XANES) spectroscopy at $\mathrm{Cu}$ and $\mathrm{Nb} K$-edges were collected by the transparent method on the BL14B2 beamline at SPring-8. The magnetic susceptibility data were recorded using a SQUID magnetometer MPMS-XL (Quantum Design) between 5 and $300 \mathrm{~K}$ under an applied field of $100 \mathrm{Oe}$.

Electronic and crystal structure of $\mathrm{CuNbO}_{3}$ and related compounds were calculated within the framework of density functional theory using the projector augmentedwave (PAW) method ${ }^{39}$ implemented in the Vienna Ab-initio Simulation Package (VASP) code. ${ }^{40-42}$ The cut-off energy of plane waves set to $600 \mathrm{eV}$. The $k$-points sampling was performed by $\Gamma$-centered Monkhorst-Pack ${ }^{43} 4 \times 4 \times 3,4 \times 4 \times 4$, and $6 \times 6 \times 6$ meshes for $P c$ perovskite-type and $R 3 c \mathrm{LiNbO}_{3}$ type $\mathrm{CuNbO}_{3}$ and $\mathrm{Cu}_{2} \mathrm{O}$, respectively. Exchangecorrelational functional were evaluated with the PBEsol functional. ${ }^{44}$ The effect of Hubbard $U$ was considered using Dudarev's approach. ${ }^{45}$ The effective on-site Coulomb term,

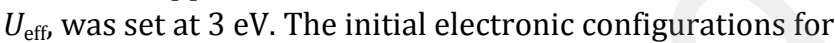
PAW potentials were $3 s^{2} 3 p^{6} 3 d^{10} 4 p^{1}, 1 s^{2} 2 s^{1}, 4 s^{2} 4 p^{6} 5 s^{2}$ $4 \mathrm{~d}^{3}$, and $2 \mathrm{~s}^{2} 2 \mathrm{p}^{6}$ for $\mathrm{Cu}, \mathrm{Li}, \mathrm{Nb}$, and $\mathrm{O}$, respectively. The crystal structures were fully optimized until residual forces and stresses were less than $1.0 \times 10^{-4} \mathrm{eV}^{-3}$ and $1.0 \times 10^{-3} \mathrm{eV}$ $\AA^{-3}$, respectively. Convergence tests were performed by comparing the results with more severe conditions, e.g., 800 $\mathrm{eV}$ and two times denser $k$-meshes. We confirmed that total energies were converged within $3 \mathrm{meV}$ atoms ${ }^{-1}$.

Lattice dynamics calculations were performed using Parlinski-Li-Kawazoe method implemented by phonopy code. $^{46-50}$ We used $2 \times 2 \times 2$ rhombohedral supercell for $\mathrm{LiNbO}_{3}$-type $\mathrm{CuNbO}_{3}$.

We also performed $\mathrm{Cu}-K$ XANES calculations with the full-potential linearized augmented plane wave plus local orbitals method and the PBEsol $+U\left(U_{\text {eff }}=3 \mathrm{eV}\right)$ functional available in the WIEN2k code. ${ }^{51,52}$ A core-hole was directly treated for final state calculations. The cut-off parameter of the plane wave, $R_{\mathrm{MT}} K_{\mathrm{MAX}}$, was set to 6.0 bohr $\mathrm{Ry}^{1 / 2}$. Calculated spectra were broadened by Lorenz functions with a natural width of $\mathrm{Cu}-K$ shell. ${ }^{53}$ To correct the calculated transition energies, the calculated $\mathrm{Cu}-K$ XANES spectra in the present study were shifted by $-29.0 \mathrm{eV}$, which corresponds to a transition-energy difference between the theoretical and experimental $\mathrm{Cu}-K \mathrm{XANES}$ for the reference material, $\mathrm{Cu}_{2} \mathrm{O}$.

\section{RESULTS}

3.1. Crystal Structure: $\mathrm{HP}-\mathrm{CuNbO}_{3}$ was previously prepared at $6.5 \mathrm{GPa}$ and $1273-1473 \mathrm{~K}$ and reported to adopt a monoclinic symmetry with $a=3.836 \AA$ ( $\left.\approx a_{\mathrm{pc}}\right), b=$ $10.432 \AA\left(\approx 2 \sqrt{2} a_{\mathrm{pc}}\right), c=5.546 \AA\left(\approx \sqrt{2} a_{\mathrm{pc}}\right)$, and $\beta=94.66^{\circ} .33$ In this study, we found that the higher-purity samples tend to be obtained by the use of the higher synthesis pressure ( $12 \mathrm{GPa}$ ) (see Figure S1 in Supporting Information).

First, we performed ED for the high-purity samples to deduce the crystal symmetry of $\mathrm{HP}-\mathrm{CuNbO}$. Figure 1 shows the ED patterns at room temperature along the [001], [010], and [100] zone axes. In contrast to the previous report, $^{33}$ all reflections can be indexed with another monoclinic cell with $a \approx 5.5 \AA\left(\approx \sqrt{2} a_{\mathrm{pc}}\right), b \approx 5.2 \AA\left(\approx \sqrt{2} a_{\mathrm{pc}}\right)$, $c \approx 7.7 \AA\left(\approx 2 a_{\mathrm{pc}}\right)$, and $\beta \approx 95^{\circ}$. The observations of 120 reflection at [001] and 012 reflection at [100] (see red circles in Figure 1) are indicative of a primitive monoclinic unit cell. The absence of $00 \mathrm{l}$ reflections with $l=$ odd (e.g., 001 reflection) in the [0 010$]$ pattern reveals the presence of the $c$-glide symmetry. The finite intensity of the forbidden 001 reflection along [100] is due to multiple scattering effects. Given the $0 k 0$ reflections with $k=$ odd (e.g., 010 reflections) in the [001] and [100] zone axes, one will expect the absence of the $2_{1}$ screw axis. However, when the multiple scattering effects are significant, the 010 reflections are observed even in the presence of the $2_{1}$ screw axis. Namely, the presence or absence of the $2_{1}$ screw axis cannot determined by the ED analysis alone. We thus suggest possible space groups to be $P C, P 2 / c$, or $P 2_{1} / c$.

Next, we carried out SXRD and NPD experiments at $300 \mathrm{~K}$ to identify the crystal symmetry of $\mathrm{HP}-\mathrm{CuNbO}_{3}$. The main reflections seem at first sight to be indexed with a $R 3 c$ $\left(\mathrm{LiNbO}_{3}\right.$-type) structure $(a \approx 5.2 \AA$ and $c \approx 14.0 \AA$ in $\mathrm{a}$ hexagonal setting), but the indexing of SXRD and NPD patterns with the successive dichotomy method ${ }^{36}$ indicates a monoclinic cell $a \approx 5.5 \AA\left(\approx \sqrt{2} a_{\mathrm{pc}}\right), b \approx 5.2 \AA\left(\approx \sqrt{2} a_{\mathrm{pc}}\right), c \approx$ $7.7 \AA\left(\approx 2 a_{\mathrm{pc}}\right)$ and $\beta \approx 95^{\circ}$, in good agreement with the ED analysis. Consistent with the symmetry lowering from the rhombohedral $R 3 c$ structure, the peak splitting (e. g., $01 \overline{4}_{h}$ and $110_{h}$ ) and superstructure reflections (e. g., $012_{m}$ and $102_{m}$ ) are detected in the SXRD pattern (Figure $2 \mathrm{a}$ ), where the subscript $h$ and $m$ represent the hexagonal and monoclinic unit cells, respectively. The symmetry lowering from the $R 3 c$ structure is also found from the peak splitting (e.g., $02 \overline{2}_{h}$ and $024_{h}$ ) in the NPD pattern (Figure 2b). The reflection conditions in the SXRD and NPD data, as well as in the ED data, leave $P c, P 2 / c$, or $P 2_{1} / c$ as possible space groups. The $P c$ structure is noncentrosymmetric-polar, 
while the $P 2 / c$ and $P 2_{1} / c$ structures are centrosymmetric. To identify the space group of $\mathrm{HP}-\mathrm{CuNbO}_{3}$, we additionally measured the second-order nonlinear optical properties. Our experiments confirmed an SHG activity (Figure S2 in Supporting Information), showing the noncentrosymmetric character. Therefore, the space group of $\mathrm{HP}^{-\mathrm{CuNbO}_{3}}$ is found to be $P C$.

The structural relationship between the $P C$ and $R 3 c$ phases is a maximal non-isomorphic group/subgroup with the following transformation matrix:

$$
\left(\begin{array}{l}
a_{m} \\
b_{m} \\
c_{m}
\end{array}\right)=\left(\begin{array}{ccc}
-1 / 3 & -2 / 3 & 1 / 3 \\
-1 & 0 & 0 \\
-2 / 3 & -4 / 3 & -1 / 3
\end{array}\right)\left(\begin{array}{l}
a_{h} \\
b_{h} \\
c_{h}
\end{array}\right),
$$

where $a_{m}, b_{m}$, and $c_{m}$ are the lattice parameters of the monoclinic unit cell, and $a_{h}, b_{h}$, and $c_{h}$ are the lattice parameters in the hexagonal setting of the rhombohedral $R 3 c$ unit cell. To the best of our knowledge, simple $A B \mathrm{O}_{3}$ perovskites crystallizing in $P c$ with $a_{m} \approx \sqrt{2} a_{\mathrm{pc}}, b_{m} \approx \sqrt{2} a_{\mathrm{pc}}$, and $c_{m} \approx 2 a_{\mathrm{pc}}$ unit cell have not been discovered yet.

Rietveld refinements were performed against NPD and SXRD patterns of $\mathrm{HP}^{-\mathrm{CuNbO}_{3}}$ at $300 \mathrm{~K}$ by assuming as an initial model a $P c$ unit cell with a $\sqrt{2} a_{\mathrm{pc}} \times \sqrt{2} a_{\mathrm{pc}} \times 2 a_{\mathrm{pc}}$ unit cell. The initial structural model was derived from the group-subgroup relationship with an $R 3 c$ ( $\mathrm{LiNbO}_{3}$-type) model using the program ISODISTORT of the ISOTROPY Software Suite, ${ }^{54}$ and confirmed by structure solution against the SXRD data using direct methods. The Nb1 position is fixed to $(0,0,0)$. Figure $3 a, b$ displays the refinement results for SXRD and NPD data, respectively. For the SXRD data, the presence of heavy $\mathrm{Nb}$ and $\mathrm{Cu}$ atoms leads to a very low contrast for oxygen atoms. The $B_{\text {iso }}$ of oxygen atoms were accordingly fixed to the $B_{\text {iso }}$ value of $\mathrm{Nb} 2$. The stoichiometric composition models provide good overall fits to the observed patterns for both SXRD (weighted profile $R$ factor $R_{\mathrm{wp}}=11.60 \%$ and Bragg $R$ factor $R_{\mathrm{B}}=6.62 \%$ ) and NPD data $\left(R_{\mathrm{wp}}=10.34 \%\right.$ and $\left.R_{\mathrm{B}}=3.66 \%\right)$. The cation site occupancies were refined to check deviations in the stoichiometry, but the refined occupancies remained within 1 or $2 \%$ of the expected full site values. This result is in agreement with complementary ICP-OES analysis in which the cationic ratio is almost stoichiometric $(\mathrm{Cu} / \mathrm{Nb}=1.05)$ within standard uncertainties.

We also examined the possibility of cation mixing on the $A$-site. According to the previous structural analyses on $\mathrm{LiNbO}_{3}$, the cation distribution was estimated to be $\left(\mathrm{Li}_{1-5 x} \mathrm{Nb}_{x} \square_{4 x}\right) \mathrm{NbO}_{3}$, where $\square$ represents a vacancy. ${ }^{55,56}$ In the course of our refinements against SXRD and NPD data, the introduction of a small amount of $\mathrm{Nb}$ (a few percent) at the $\mathrm{Cu} 1$ or $\mathrm{Cu} 2$ sites did not improve the fitting quality. The refined structural parameters from SXRD and NPD data are listed in Table $\mathbf{1}$ and Table 2 , respectively. The selected bond lengths and bond angles are tabulated in Table S1.
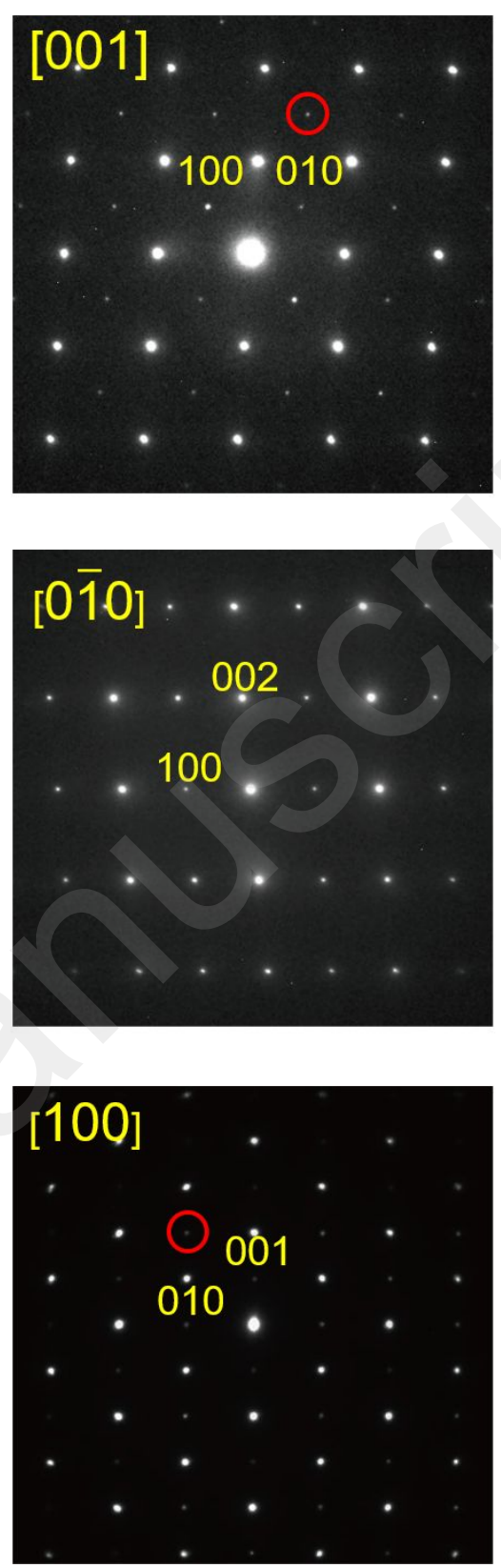

Figure 1. ED patterns of $\mathrm{HP}-\mathrm{CuNbO}_{3}$ at room temperature taken along [001], [0 $\overline{1} 0]$, and [100] zone axes. Representative indices are shown just above the corresponding reflection spots. The reflections marked in red are indicative of a primitive cell.

The calculated density of $\mathrm{HP}^{-\mathrm{CuNbO}_{3}}\left[6.12 \mathrm{~g} \mathrm{~cm}^{-3}\right.$ (SXRD) and $6.14 \mathrm{~g} \mathrm{~cm}^{-3}$ (NPD)] is significantly larger than that of $\mathrm{AP}^{-} \mathrm{CuNbO}_{3}\left(5.02 \mathrm{~g} \mathrm{~cm}^{-3}\right),{ }^{28}$ consistent with the expectation that the high-pressure synthesis provides a higher-density phase. Bond-valence-sum calculations ${ }^{8}$ using the NPD (SXRD)-refined bond lengths give $+0.93(3)(+0.85(2))$, $+0.99(2)(+0.84(2)),+4.85(7)(+5.04(8))$, and $+4.84(8)$ 

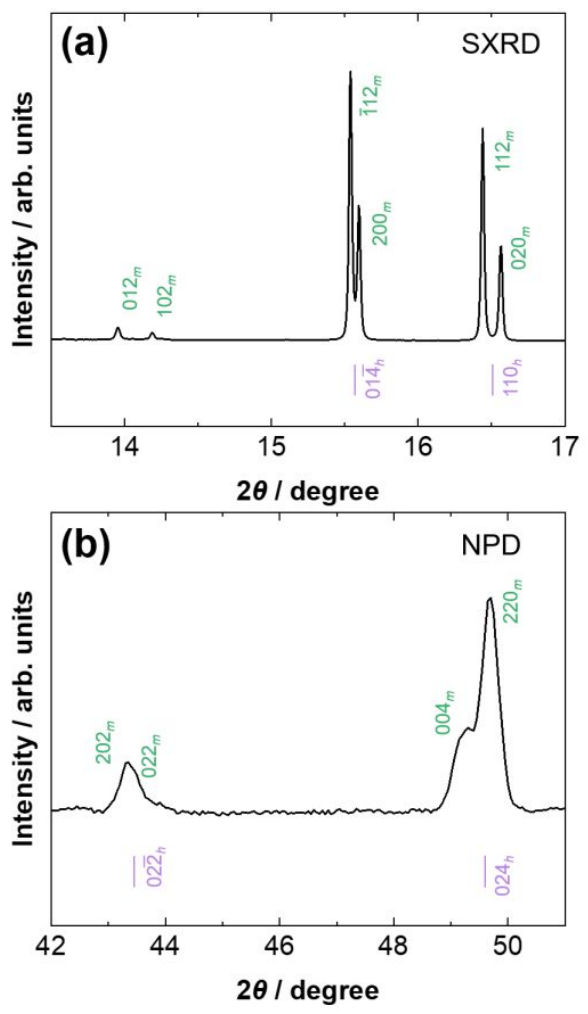

Figure 2. Enlarged portions of (a) SXRD $(\lambda=0.75003 \AA)$ and (b) NPD $(\lambda=1.594 \AA)$ patterns of $\mathrm{HP}-\mathrm{CuNbO}_{3}$ at $300 \mathrm{~K}$. Some reflections in the observed patterns are split by a monoclinic distortion from the rhombohedral $R 3 c$ structure; the purple ticks correspond to the positions of the allowed Bragg reflections for the $R 3 c$ structure. The subscript $h$ represents the rhombohedral unit cell in a hexagonal setting, and the subscript $m$ indicates the monoclinic unit cell.

$(+4.76(8))$ for $\mathrm{Cu} 1, \mathrm{Cu} 2, \mathrm{Nb} 1$, and $\mathrm{Nb} 2$, respectively, confirming the $\mathrm{Cu}^{+} \mathrm{Nb}^{5+} \mathrm{O}_{3}$ ionic model. This result conforms to those of XANES and temperature-dependent magnetic susceptibility experiments, which will be separately described below. Figure 4 depicts the crystal structures of $\mathrm{HP}_{-} \mathrm{CuNbO}_{3}$ refined against the NPD data at $300 \mathrm{~K}$. The monoclinic distortion of $\mathrm{HP}-\mathrm{CuNbO}_{3}$ highlights the tilting distortion of $\mathrm{NbO}_{6}$ octahedra and the off-center displacements of $\mathrm{Nb}^{5+}$ ions. The octahedral tilt system is $a^{-} a^{-} c^{-}$. Glazer ${ }^{17}$ has shown that this tilt system in an aristotype cubic $P m \overline{3} m$ perovskite leads to a centrosymmetric monoclinic $C 2 / c$ structure. In $\mathrm{HP}-\mathrm{CuNbO}_{3}$ perovskite, the symmetry is lowered to the space group $P c$ by the two inequivalent off-center displacements of $\mathrm{Nb}^{5+}$ ions (see arrows in Figure 4b).

In $A_{3} O_{3}$ perovskite oxides, the decrease in the $A$-site ionic radius, i.e., the reduction in the tolerance factor $t$, results in enhanced octahedral tilting, leading to the decrease of the
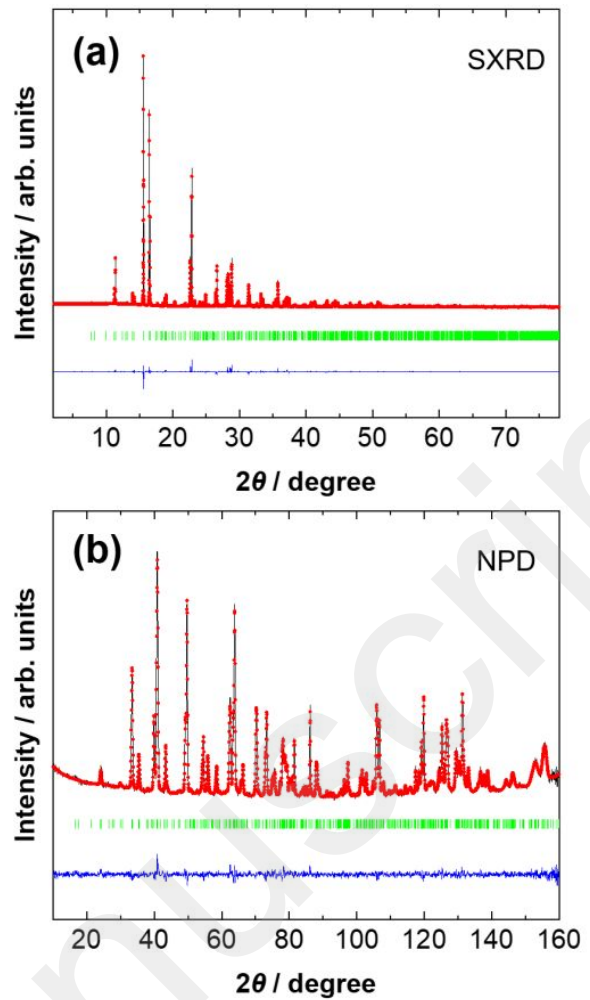

Figure 3. Rietveld refinements against (a) SXRD $(\lambda=0.75003 \AA)$ and (b) NPD $(\lambda=1.594 \AA)$ patterns of $\mathrm{HP}^{-\mathrm{CuNbO}_{3}}$ at $300 \mathrm{~K}$. These refinements were performed on the basis of the monoclinic Pc perovskite-type structure model with a $\sqrt{\mathbf{2}} a_{\mathrm{pc}} \times$ $\sqrt{\mathbf{2}} a_{\mathrm{pc}} \times 2 a_{\mathrm{pc}}$ unit cell, showing the observed (red circles) and calculated (black solid lines) profiles. The blue solid lines represent the difference between the observed and calculated profiles. The green ticks correspond to the positions of the allowed Bragg reflections.

$B-0-B$ bond angle. As expected from the small $t$ value $(t=$ 0.89 ), the $P c$ phase of $\mathrm{HP}^{-\mathrm{CuNbO}_{3}}$ possesses a notable magnitude of $\mathrm{NbO}_{6}$ octahedral tilts, with the $\mathrm{Nb}-\mathrm{O}-\mathrm{Nb}$ angles deviating significantly from the ideal value of $180^{\circ}$ by up to $\sim 36^{\circ}$ (see Table $\mathbf{S 1}$ ). The $\mathrm{Nb}-\mathrm{O}-\mathrm{Nb}$ bond angles of

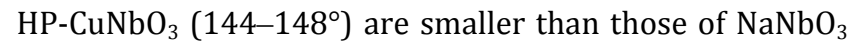
$\left(157-162^{\circ}\right),{ }^{22}$ but are larger than that of $\mathrm{LiNbO}_{3}\left(140^{\circ}\right) \cdot^{15}$ Namely, the average $\mathrm{Nb}-\mathrm{O}-\mathrm{Nb}$ bond angle decreases in the order $\mathrm{NaNbO}_{3}(t=0.97)>\mathrm{CuNbO}_{3}(t=0.89)>\mathrm{LiNbO}_{3}(t=$ 0.85), demonstrating the $A$-site-cation-size-dependent octahedral tilting. In $P c \mathrm{CuNbO}_{3}$, the coordination environments of the two independent $\mathrm{Nb}$ sites, $\mathrm{Nb} 1$ and $\mathrm{Nb2}$, are strongly asymmetric, due to their off-center displacements along [001] $\left(=<100>_{\mathrm{pc}}\right)$ within the octahedra (see Figure 4b). The $\mathrm{NbO}_{6}$ octahedral distortion $\Delta$ of HP$\mathrm{CuNbO}_{3}$ was calculated from the NPD-refined bond lengths; $\Delta=1 / 6 \Sigma_{i}\left[\left(d_{i}-\langle d\rangle\right) /\langle d\rangle\right]^{2}$, where $d_{i}$ is the individual $\mathrm{Nb}-0$ bond length and $\langle d\rangle$ is the average $\mathrm{Nb}-\mathrm{O}$ bond length 
(a)

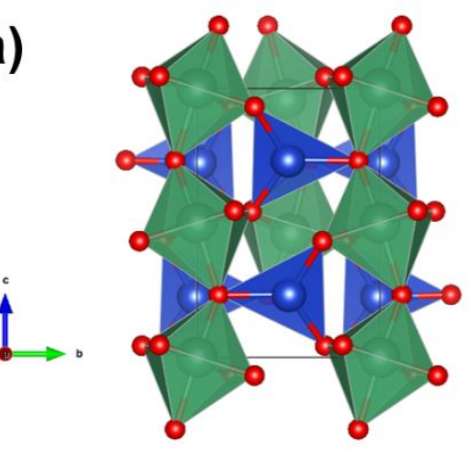

(b)

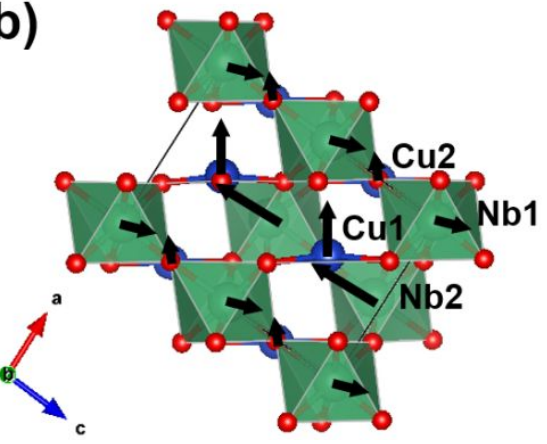

Figure 4. The refined crystal structures of $\mathrm{HP}_{-} \mathrm{CuNbO}_{3}$ from the NPD data at $300 \mathrm{~K}$. The structural views in (a) $b c$ and (b) $a c$ planes are shown. The arrows in (b) indicate the cation displacements from the closed-packed oxygen planes and those from the centroids of $\mathrm{NbO}_{6}$ octahedra. (see Table S1). We obtained $\Delta\left(\mathrm{Nb}_{6} \mathrm{O}_{6}\right)=1.5(2) \times 10^{-3}$ and $\Delta\left(\mathrm{Nb}^{2} \mathrm{O}_{6}\right)=2.9(1) \times 10^{-3}$. The magnitude of these octahedral distortions is comparable to that for other perovskite niobates $\mathrm{ANbO}_{3}$ with second-order Jahn-Teller active $\mathrm{Nb}^{5+}\left(4 \mathrm{~d}^{0}\right)$ ions (e.g., 3.11(1) $\times 10^{-3}$ for $\mathrm{LiNbO}_{3}{ }^{15}$ and $4.0(3) \times$ $10^{-3}$ for $\left.\mathrm{KNbO}_{3}\right)^{11}$ The large octahedral distortions for HP$\mathrm{CuNbO}_{3}$ are thus ascribed to the second-order Jahn-Teller effects.

Asymmetric environments are also observed for the $\mathrm{Cu}$ coordination in $\mathrm{PC} \mathrm{CuNbO}_{3}: \mathrm{Cu}$ atoms are displaced approximately along $[20 \overline{3}]\left(=[111]_{\mathrm{pc}}\right)$ with respect to the oxygen-triangle planes, occupying two independent $\mathrm{Cu}$ sites, $\mathrm{Cu} 1$ and $\mathrm{Cu} 2$ (see Figure 4b). Each of $\mathrm{Cu} 1$ and $\mathrm{Cu} 2$ atoms forms three shorter and nine longer bonds with the oxygen atoms (see also Table S1), although the $A$-site cations in aristotype perovskites are surrounded by 12 equidistant anions. The distances of the longer $\mathrm{Cu}-\mathrm{O}$ bonds (2.64(3)-

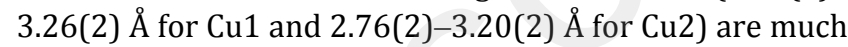
larger than those of the shorter $\mathrm{Cu}-0$ bonds (2.01(3), 2.04(3), 2.08(1) $\AA$ for $\mathrm{Cu} 1$ and 2.00(1), 2.03(2), 2.03(2) $\AA$ for $\mathrm{Cu} 2$ ), and so the effective coordination number of $\mathrm{Cu}$ atoms is three. The coordination environments of $\mathrm{Cu}_{3} \mathrm{O}_{3}$ and $\mathrm{Cu} 2 \mathrm{O}_{3}$ differ in terms of polyhedral distortions and average bond lengths. The displacement from the centers of oxygen triangles is about nine times larger for $\mathrm{Cu} 1$ than for $\mathrm{Cu} 2$ (see Figure $4 \mathrm{~b}$ and Figure 11).

Table 1. Structural Parameters of $\mathrm{HP}-\mathrm{CuNbO}_{3}$ at $300 \mathrm{~K}$ Obtained from Refinements against the SXRD Data

\begin{tabular}{|c|c|c|c|c|c|c|}
\hline atom & site & $g$ & $x$ & $y$ & $z$ & $U_{\text {iso }} / \AA^{2}$ \\
\hline $\mathrm{Cu} 1$ & $2 a$ & 1 & $0.5269(4)$ & $0.9961(19)$ & $0.2100(3)$ & $0.0153(7)$ \\
\hline $\mathrm{Cu} 2$ & $2 a$ & 1 & $0.9986(4)$ & $0.4953(17)$ & $0.7206(3)$ & $0.0082(6)$ \\
\hline $\mathrm{Nb} 1$ & $2 a$ & 1 & 0 & 0 & 0 & $0.0100(5)$ \\
\hline $\mathrm{Nb} 2$ & $2 a$ & 1 & $0.4910(3)$ & $0.5074(6)$ & $0.4513(2)$ & $0.0020(3)$ \\
\hline 01 & $2 a$ & 1 & $0.183(3)$ & $0.687(3)$ & $0.428(2)$ & $0.0020(3)$ \\
\hline 02 & $2 a$ & 1 & $0.691(3)$ & $0.193(3)$ & $0.928(2)$ & $=U_{\text {iso }}(01)$ \\
\hline 03 & $2 a$ & 1 & $0.289(3)$ & $0.204(3)$ & $0.537(2)$ & $=U_{\text {iso }}(01)$ \\
\hline 04 & $2 a$ & 1 & $0.791(3)$ & $0.707(3)$ & $0.028(2)$ & $=U_{\mathrm{iso}}(01)$ \\
\hline 05 & $2 a$ & 1 & $0.962(2)$ & $0.103(3)$ & $0.227(1)$ & $=U_{\mathrm{iso}}(01)$ \\
\hline 06 & $2 a$ & 1 & $0.475(2)$ & $0.612(2)$ & $0.716(1)$ & $=U_{\text {iso }}(01)$ \\
\hline
\end{tabular}

Space group: $P c$ (No. 7), $Z=4 . \mathrm{CuNbO}_{3}\left(\mathrm{fw}=204.45 \mathrm{~g} \mathrm{~mol}^{-1}\right): \lambda=0.75003 \AA, 0.595 \AA<d<20.2 \AA$; lattice parameters: $a=5.54535(4)$ $\AA, b=5.21029(3) \AA, c=7.67491(6) \AA, \beta=94.6924(6)^{\circ}$, and $V=221.007(3) \AA^{3}, R_{\mathrm{wp}}=11.60 \%$ and $R_{\mathrm{B}}=6.62 \% ; R_{\mathrm{wp}}=\left[\Sigma w_{i}\left(y_{i \mathrm{o}}-y_{i c}\right)^{2} /\right.$ $\left.\Sigma w_{i} y_{i 0}{ }^{2}\right]^{1 / 2}$, where $y_{i \mathrm{o}}$ and $y_{i \mathrm{c}}$ are the observed and calculated intensities, respectively, and $w_{i}$ is the weighting factor. $R_{\mathrm{B}}=\Sigma \mid I_{0}\left(h_{K}\right)-$ $I_{\mathrm{c}}\left(h_{K}\right)|/ \Sigma| I_{\mathrm{o}}\left(h_{K}\right) \mid$, where $I_{\mathrm{o}}\left(h_{K}\right)$ and $I_{\mathrm{c}}\left(h_{K}\right)$ are the observed and calculated integrated intensities for reflection $K$, respectively. 


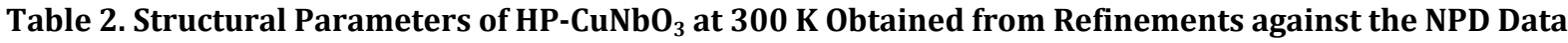

\begin{tabular}{ccccccc} 
atom & site & $g$ & $x$ & $y$ & $z$ & $U_{\text {eq/iso }} / \AA^{2}$ \\
\hline $\mathrm{Cu} 1$ & $2 a$ & 1 & $0.514(4)$ & $0.988(2)$ & $0.226(2)$ & $0.065(5)$ \\
$\mathrm{Cu} 2$ & $2 a$ & 1 & $0.989(2)$ & $0.498(2)$ & $0.735(2)$ & $0.011(1)$ \\
$\mathrm{Nb} 1$ & $2 a$ & 1 & 0 & 0 & 0 & $0.094(13)$ \\
$\mathrm{Nb} 2$ & $2 a$ & 1 & $0.4830(14)$ & $0.5122(14)$ & $0.4610(8)$ & $0.015(2)$ \\
01 & $2 a$ & 1 & $0.184(2)$ & $0.686(2)$ & $0.433(2)$ & $0.007(1)$ \\
02 & $2 a$ & 1 & $0.686(3)$ & $0.185(2)$ & $0.935(2)$ & $0.014(2)$ \\
03 & $2 a$ & 1 & $0.290(3)$ & $0.205(2)$ & $0.546(2)$ & $0.005(2)$ \\
04 & $2 a$ & 1 & $0.795(3)$ & $0.701(2)$ & $0.043(2)$ & $0.002(2)$ \\
05 & $2 a$ & 1 & $0.993(3)$ & $0.119(2)$ & $0.233(2)$ & $0.007(1)$ \\
06 & $2 a$ & 1 & $0.491(3)$ & $0.613(2)$ & $0.733(2)$ & $0.008(2)$
\end{tabular}

Space group: $P c$ (No. 7), $Z=4 . \mathrm{CuNbO}_{3}\left(\mathrm{fw}=204.45 \mathrm{~g} \mathrm{~mol}^{-1}\right): \lambda=1.594 \AA, 0.809 \AA<d<6.11 \AA$; lattice parameters: $a=5.548088(10)$ $\AA, b=5.208766(9) \AA, c=7.695716(15) \AA, \beta=94.67983(10)^{\circ}$, and $V=221.6547(7) \AA^{3}, R_{\mathrm{wp}}=10.34 \%$ and $R_{\mathrm{B}}=3.66 \%$. Cu1 was refined anisotropically.

Interestingly, we notice that the perovskite-type HP$\mathrm{CuNbO}_{3}$ has the same crystal symmetry and unit-cell metrics as the lowest-temperature monoclinic phase of $\mathrm{WO}_{3}, \varepsilon-\mathrm{WO}_{3}{ }^{57}$ Namely, both of them crystallize in $P c$ symmetry with $a_{m} \approx \sqrt{2} a_{\mathrm{pc}}, b_{m} \approx \sqrt{2} a_{\mathrm{pc}}$, and $c_{m} \approx 2 a_{\mathrm{pc}}$. Note that the structure of $\mathrm{WO}_{3}$ can be regarded as an $\mathrm{ABO}_{3}$ perovskite-type structure with empty $A$-sites. In the $P C$ structure, the $B 1$ and $B 2$ atoms $\left(B=\mathrm{Nb}\right.$ in $\mathrm{HP}-\mathrm{CuNbO}_{3}$ or $\mathrm{W}$ in $\varepsilon$ - $\mathrm{WO}_{3}$ ) undergo almost antiparallel off-center displacements along [001] $\left(=<100>_{\mathrm{pc}}\right)$ within the octahedra. For $\varepsilon-\mathrm{WO}_{3}$, the antiparallel displacements of $\mathrm{W} 1$ and $\mathrm{W} 2$ atoms with different amplitudes produce "collinear ferrielectricity". For $\mathrm{HP}^{-\mathrm{CuNbO}} \mathrm{N}_{3}$ the antiparallel displacements of $\mathrm{Nb} 1$ and $\mathrm{Nb} 2$ with different magnitudes are accompanied by the parallel displacements of $\mathrm{Cu} 1$ and Cu2 atoms approximately along $[20 \overline{3}] \quad\left(=[111]_{\mathrm{pc}}\right)$. Consequently, a noncollinear ferrrielectric structure appears in the $P C$ phase of $\mathrm{HP}-\mathrm{CuNbO}_{3}$. The spontaneous polarization calculated from the NPD-refined crystal structure using the formal charges of $\mathrm{Cu}^{+}$and $\mathrm{Nb}^{5+}$ is $9.7 \mu \mathrm{C}$ $\mathrm{cm}^{-2}$.

It is worth underlining that ferrielectricity is observed in $\mathrm{AgNbO}_{3}$, but it stems from collinear electric dipole order. On the other hand, $\mathrm{HP}-\mathrm{CuNbO}_{3}$ is a rare example of a ferrielectric material with noncollinear electric dipole order, representing a new type of polar phase in the perovskite structure.

3.2. Valence state: Figure $5 \mathrm{a}$, b displays the experimental and calculated XANES spectra at the $\mathrm{Cu} K$-edge, respectively. The experimental $\mathrm{Cu}$ absorption edge position of HP$\mathrm{CuNbO}_{3}$ is close to that of $\mathrm{Cu}_{2} \mathrm{O}$, but different from that of
$\mathrm{CuO}$. The contrasting coordination environment between $\mathrm{HP}^{-\mathrm{CuNbO}_{3}}$ (perovskite $A$-site) and $\mathrm{Cu}_{2} \mathrm{O}$ (linear coordination), however, makes it difficult to estimate clearly the $\mathrm{Cu}$ valency in $\mathrm{HP}-\mathrm{CuNbO}_{3}$. So, we performed

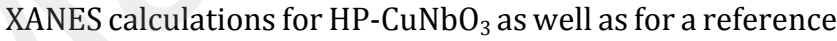
compound, $\mathrm{Cu}_{2} \mathrm{O}$ (Figure $5 \mathrm{~b}$ ). The experimental spectra for $\mathrm{HP}-\mathrm{CuNbO}_{3}$ and $\mathrm{Cu}_{2} \mathrm{O}$ matches qualitatively the calculated spectra based on $\mathrm{Cu}^{+} \mathrm{Nb}^{5+} \mathrm{O}_{3}$ and $\mathrm{Cu}_{2}^{+} \mathrm{O}$ models, respectively, revealing that the $\mathrm{Cu}$ cations are present as $\mathrm{Cu}^{+}$in both compounds. On the other hand, the $\mathrm{Nb}$ valency in HP$\mathrm{CuNbO}_{3}$ can be easily estimated to be +5 from the similarity of its experimental spectrum to that of $\mathrm{Nb}_{2} \mathrm{O}_{5}$ (Figure 6). Thus, our XANES analyses unambiguously evidence that the valence states in $\mathrm{CuNbO}_{3}$ are +1 for $\mathrm{Cu}$ and +5 for $\mathrm{Nb}$.

Figure 7 gives the temperature dependence of magnetic

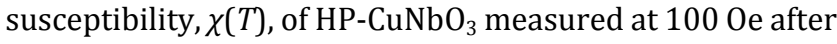
zero-field cooling. The fitting was carried out on the basis of the Curie-Weiss law described by the following equation:

$$
\chi(T)=\chi_{0}+\frac{N \mu_{\text {eff }}^{2}}{3 k_{B}\left(T-\theta_{\mathrm{w}}\right)},
$$

where $\chi_{0}$ is a temperature-independent term, $N$ the Avogadro constant, $\mu_{\text {eff }}$ the effective magnetic moment, $k_{\mathrm{B}}$ the Boltzmann constant, and $\Theta_{\mathrm{w}}$ the Weiss temperature. The fitting results are $\chi_{0}=-2.6(1) \times 10^{-4} \mathrm{emu} \mathrm{Oe}^{-1} \mathrm{~mol}^{-1}, \Theta_{\mathrm{w}}=$ $-1.8(2) \mathrm{K}$, and $\mu_{\text {eff }}=0.301(6) \mu_{\mathrm{B}}$. The calculated effective magnetic moment is significantly smaller than that for $\mathrm{Cu}^{2+}$ $\left(1.732 \mu_{\mathrm{B}}\right)$. The paramagnetic behavior is thus attributed to a small amount of magnetic impurities. In addition, $\chi(T)$ is negative above $50 \mathrm{~K}$, with the absolute values being larger 

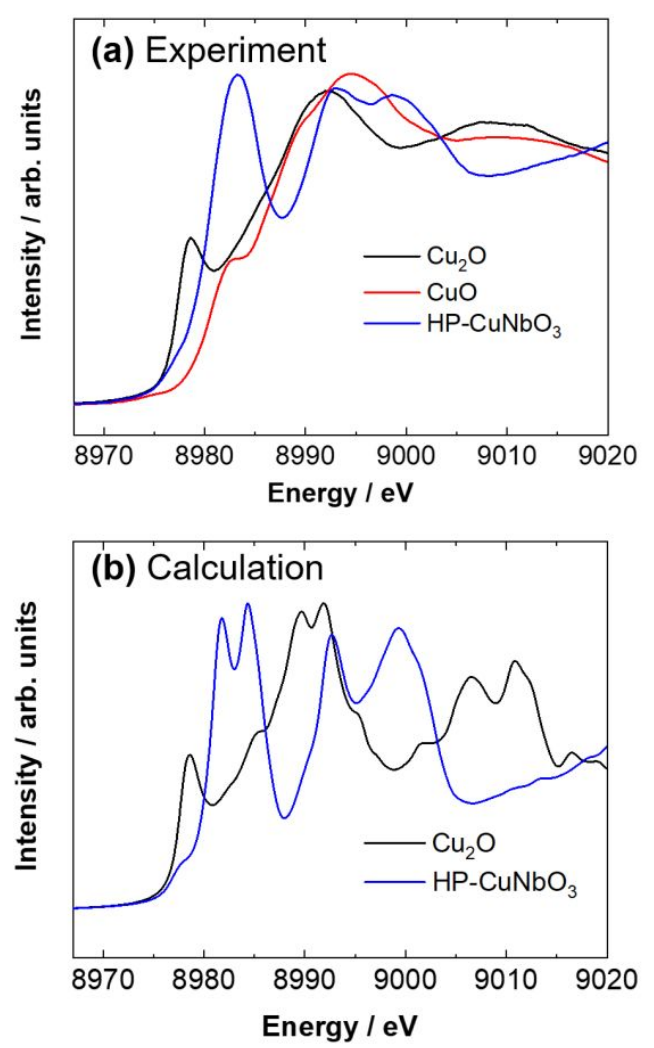

Figure 5. (a) The experimental $\mathrm{Cu} K$-edge XANES spectrum of $\mathrm{HP}-\mathrm{CuNbO}_{3}$ (blue) in comparison with those of $\mathrm{Cu}_{2} \mathrm{O}$ (black) and $\mathrm{CuO}$ (red). (b) The calculated $\mathrm{Cu} K$-edge XANES spectra of $\mathrm{HP}_{-} \mathrm{CuNbO}_{3}$ (blue) and $\mathrm{Cu}_{2} \mathrm{O}$ (black).

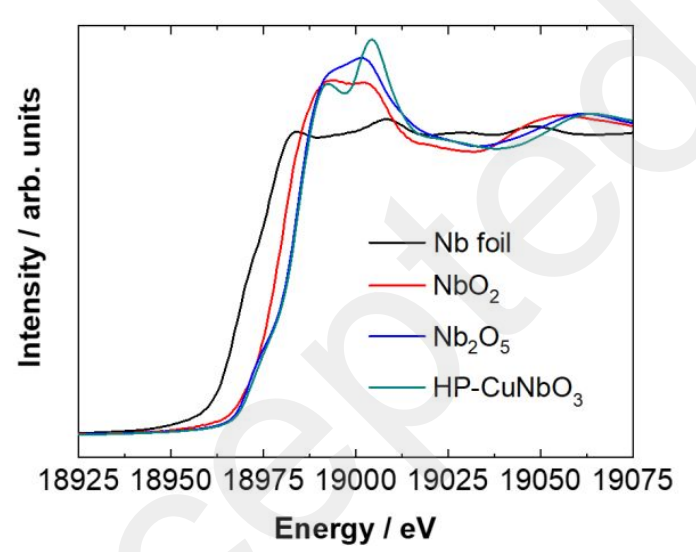

Figure 6. The experimental $\mathrm{Nb} K$-edge XANES spectrum of HP$\mathrm{CuNbO}_{3}$ (green) in comparison with those of $\mathrm{Nb}$ foil (black), $\mathrm{NbO}_{2}$ (red), and $\mathrm{Nb}_{2} \mathrm{O}_{5}$ (blue).

than those of the container used for the measurement. These facts mean that $\mathrm{HP}-\mathrm{CuNbO}_{3}$ is diamagnetic and has closed-shell cations, $\mathrm{Cu}^{+}\left(\mathrm{d}^{10}\right)$ and $\mathrm{Nb}^{5+}\left(\mathrm{d}^{0}\right)$.

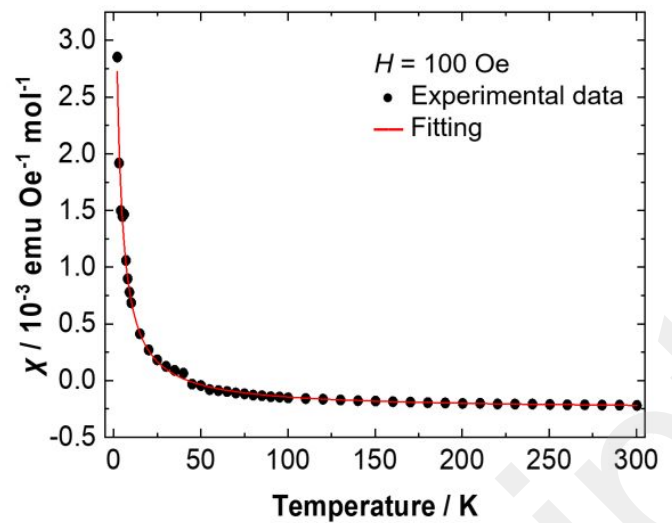

Figure 7. Temperature dependence of magnetic susceptibility,

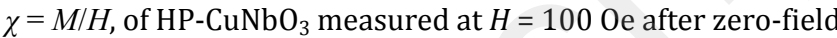
cooling. The dots represent the observed data, while the red solid line is the fitted curve according to the Curie-Weiss law.

3.3. Temperature-driven phase transition: Figure 8a,b shows temperature-variable SXRD patterns upon heating $\mathrm{HP}^{-} \mathrm{CuNbO}_{3}$ above $300 \mathrm{~K}$ under ambient pressure. The heating rate was set to $20 \mathrm{~K} \mathrm{~min}^{-1}$ and the waiting time at each temperature was $1 \mathrm{~min}$. One can see that the peak splittings observed at $300 \mathrm{~K}$, which arise from the monoclinic distortion, disappear at $470 \mathrm{~K}$. This fact is indicative of the phase transition from a monoclinic $P c$ phase into a higher-symmetry rhombohedral phase. Considering the reflection conditions for the hightemperature phase in the hexagonal setting $(-h+k+l=3 n$ for $h k l, h+l=3 n$ and $l=2 n$ for $h \bar{l} l, l=3 n$ for $h h l$, and $l=6 n$ for $00 l$ ), the possible space groups are either $R 3 c$ (noncentrosymmetric polar) or $R \overline{3} c$ (centrosymmetric nonpolar).

To deduce the space group of the high-temperature rhombohedral polymorph, we examined the temperature variation of the lattice parameters between 470 and $510 \mathrm{~K}$, and found that the $a_{h}$ parameter increases with increasing temperature, while the temperature rise results in a decrease in the $c_{h}$ parameter (see Figure $\mathbf{S 3}$ in Supporting Information). Similar behavior has been observed for $R 3 c$ ferroelectric compounds, like $\mathrm{LiNbO}_{3}, \mathrm{LiTaO}_{3},{ }^{58}$ and $\mathrm{LiOsO}_{3}, 59$ where the relaxation of the spontaneous ferroelectric strains along the $c$ axis upon heating up to the Curie temperature $\left(T_{\mathrm{C}}\right)$ leads to a decrease of the $c_{h}$ parameters and an increase of the $a_{h}$ parameters; in the absence of spontaneous strains (i.e., in the hightemperature $R \overline{3} \mathrm{c}$ phases at $T>T_{\mathrm{C}}$ ), both $a_{h}$ and $c_{h}$ parameters increase with increasing temperature, as naturally expected. Judging from the thermal evolution of the $c_{h}$ parameter for the high-temperature phase of HP$\mathrm{CuNbO}_{3}$ (i.e., decrease of the $c_{h}$ parameter upon heating), its space group is determined as a polar $R 3 c$. In other words,

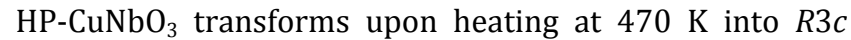
$\left(\mathrm{LiNbO}_{3}\right.$-type) $\mathrm{CuNbO}_{3}$. The pseudo-cubic lattice volumes, 

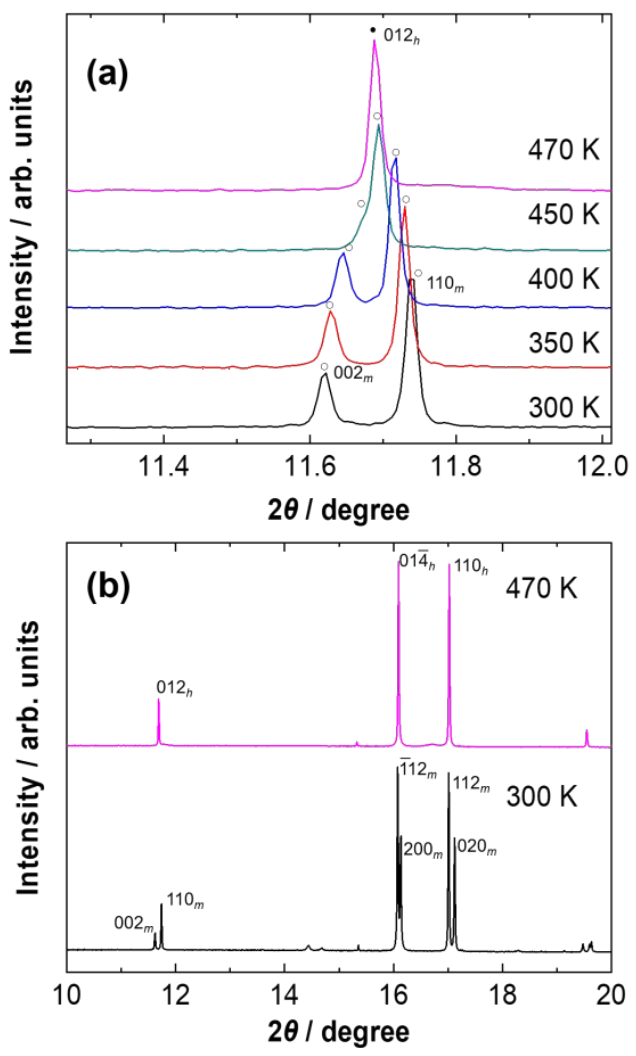

Figure 8. (a) Temperature evolution of SXRD patterns $(\lambda=$ $0.75565 \AA$ ) of $\mathrm{HP}^{-\mathrm{CuNbO}_{3}}$ in the temperature range of 300 to $470 \mathrm{~K}$. (b) Comparison between SXRD patterns at $300 \mathrm{~K}(P c)$ and at $470 \mathrm{~K}(R 3 c)$. The subscript $h$ represents the rhombohedral unit cell in a hexagonal setting, and the subscript $m$ indicates the monoclinic unit cell.

$V_{\mathrm{pc}}$ of the $P c$ and $R 3 c$ phases are plotted in Figure $\mathbf{S 4}$ against temperature; $V_{\mathrm{pc}}$ was calculated by dividing the lattice volume by $Z$ ( $Z=4$ for $P C$ and $Z=6$ for $R 3 c$ ). A continuous change in $V_{\mathrm{pc}}$ across the $P c-R 3 c$ transition is indicative of a second-order phase transition, consistent with the group theoretical analysis.

The Rietveld plot of the $R 3 c \mathrm{CuNbO}_{3}$ at $470 \mathrm{~K}$ is shown in Figure 9a. The refined structure is displayed in Figure 9b and the refined structural parameters are given in Table 3. The $\mathrm{Nb} 1$ position is fixed to $(0,0,0)$. We refined the cation site occupancies to confirm deviations in the stoichiometry, and detected a small $\mathrm{Cu}$ defect $(g(\mathrm{Cu})=0.929(9))$. This nonstoichiometric composition model $\left(\mathrm{Cu}_{0.93} \mathrm{NbO}_{3}\right)$ leads to better overall fits than the stoichiometric composition model $\left(\mathrm{CuNbO}_{3}\right) ; R_{\mathrm{wp}}=7.91 \%$ and $R_{\mathrm{B}}=7.11 \%$ for $\mathrm{Cu}_{0.93} \mathrm{NbO}_{3}$ and $R_{\mathrm{wp}}=7.92 \%$ and $R_{\mathrm{B}}=11.4 \%$ for $\mathrm{CuNbO}_{3}$. The formation of $\mathrm{Cu}$ deficiency is related to the onset of the decomposition of the $R 3 c$ phase as mentioned below, which is driven by the release of $A$-site $\mathrm{Cu}$. The calculated spontaneous polarization along [001] $\left(=[111]_{\mathrm{pc}}\right)$ for $R 3 c \mathrm{Cu}_{0.93} \mathrm{NbO}_{3}$ is 15 $\mu \mathrm{C} \mathrm{cm}^{-2}$, which is larger than that of the lower-symmetry $P c$ $\mathrm{CuNbO}_{3}$. The counterintuitive result is due to the fact that the almost antiparallel off-center displacements of $\mathrm{Nb}^{5+}$ ions in $\mathrm{Pc} \mathrm{CuNbO}_{3}$ cancel each other's polarization. It should be mentioned that the $R 3 \mathrm{c}$ phase starts to decompose at around $500 \mathrm{~K}$ to produce $\mathrm{Cu}_{2} \mathrm{O}$ and $\mathrm{CuNb}_{2} \mathrm{O}_{6}$, according to the temperature-variable SXRD experiments. The former compound, $\mathrm{Cu}_{2} \mathrm{O}$, is formed by the release of $A$-site $\mathrm{Cu}$ in the $R 3 c$ phase and its subsequent oxidation by atmospheric oxygen. The latter compound, $\mathrm{CuNb}_{2} \mathrm{O}_{6}$, is isostructural to a perovskite-type $\mathrm{CuTa}_{2} \mathrm{O}_{6}$ (cubic or pseudo-cubic). ${ }^{60,}{ }^{61}$ The thermal stability temperature range of $R 3 \mathrm{c}$ phase is so narrow that the $P c-R 3 c$ phase transition almost concurs with the decomposition reaction of the $R 3 c$ phase. Given the nominal cation valences of the final decomposition product $\left(\mathrm{Cu}^{2+} \mathrm{Nb}^{5+}{ }_{2} \mathrm{O}_{6}\right)$, we believe that a partial oxidation of $\mathrm{Cu}^{+}$to $\mathrm{Cu}^{2+}\left(\mathrm{Cu}_{0.86}^{+} \mathrm{Cu}^{2+}{ }_{0.07} \mathrm{Nb}^{5+} \mathrm{O}_{3}\right)$ will occur in $R 3 c \mathrm{Cu}_{0.93} \mathrm{NbO}_{3}$ to compensate for its $\mathrm{Cu}$ vacancies.

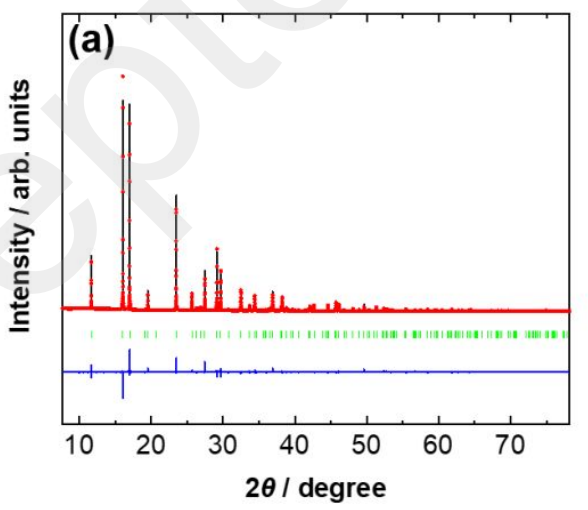

(b)
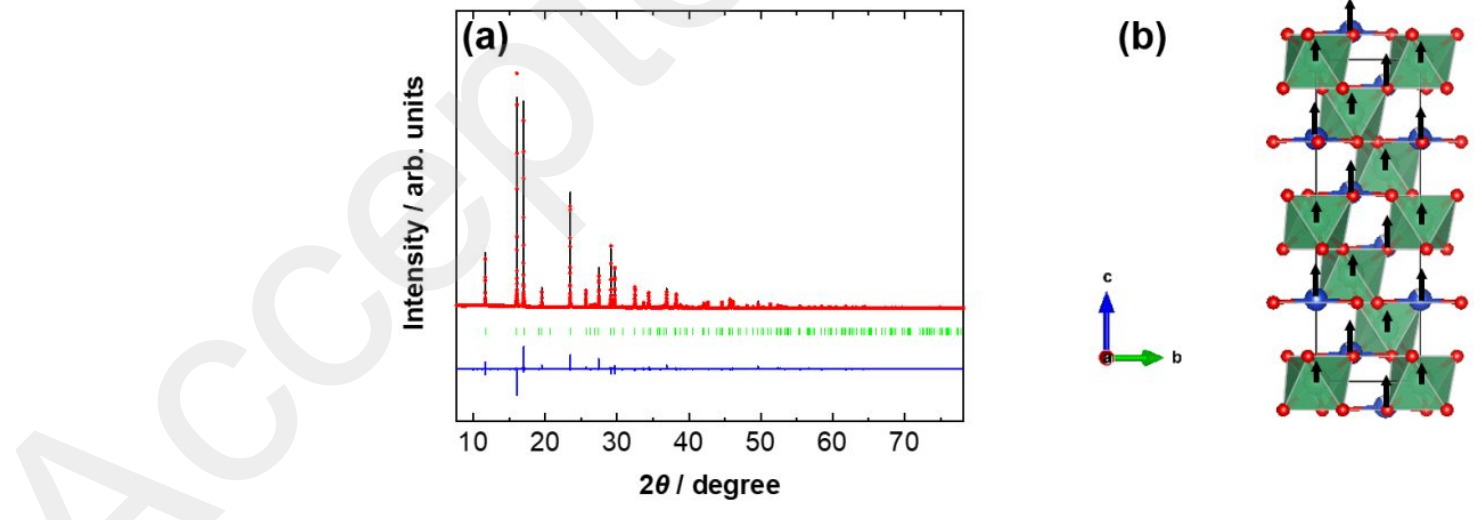

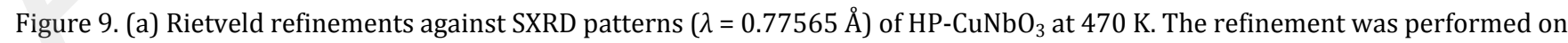
the basis of the rhombohedral $R 3 \mathrm{c}$ perovskite-type structure model with $A$-site deficiency (i.e., $\mathrm{LiNbO}_{3}$-type $\mathrm{Cu}_{0.93} \mathrm{NbO}_{3}$ ), showing the observed (red circles) and calculated (black solid lines) profiles. The blue solid lines represent the difference between the observed and calculated profiles. The green ticks correspond to the positions of the allowed Bragg reflections. Peaks due to $\mathrm{Cu}_{2} \mathrm{O}$ and $\mathrm{CuNb}_{2} \mathrm{O}_{6}$ were excluded in the refinement. (b)The refined crystal structure of $R 3 c\left(\mathrm{LiNbO}_{3}\right.$-type) $\mathrm{Cu}_{0.94} \mathrm{NbO}_{3}$ at $470 \mathrm{~K}$. The arrows indicate the cation displacements from the closed-packed oxygen planes and those from the centroids of $\mathrm{NbO}_{6}$ octahedra. 
Table 3. Structural Parameters of $\mathrm{HP}-\mathrm{CuNbO}_{3}$ at $470 \mathrm{~K}$ Obtained from Refinements against the SXRD Data

\begin{tabular}{ccccccc} 
atom & site & $g$ & $x$ & $y$ & $z$ & $U_{\mathrm{eq} / \text { iso }} / \AA^{2}$ \\
\hline $\mathrm{Cu} 1$ & $6 a$ & $0.929(9)$ & 0 & 0 & $0.255(3)$ & $0.035(3)$ \\
$\mathrm{Nb} 1$ & $6 a$ & 1 & 0 & 0 & 0 & $0.0166(7)$ \\
$\mathrm{O} 1$ & $18 b$ & 1 & $0.078(3)$ & $0.352(5)$ & $0.078(2)$ & $0.01665(1)$
\end{tabular}

Space group: $R 3 c$ (No. 161), $Z=6 . \mathrm{Cu}_{0.93} \mathrm{NbO}_{3}$ (fw $=199.9 \mathrm{~g} \mathrm{~mol}^{-1}$ ): $\lambda=0.77565 \AA, 0.615 \AA<d<6.03 \AA$; lattice parameters: $a=$ $5.2433(2) \AA, c=14.0006(4) \AA$, and $V=333.34(2) \AA^{3}, R_{\mathrm{wp}}=7.91 \%, R_{\mathrm{B}}=7.11 \%$. Cu1 and $\mathrm{Nb} 1$ were refined anisotropically.

\section{DISCUSSION}

As described above, we find two new polar polymorphs of $\mathrm{CuNbO}_{3}$. One is the monoclinic $P c$ perovskite-type phase $\left(\mathrm{HP}-\mathrm{CuNbO}_{3}\right)$ stabilized via the high-pressure and hightemperature synthesis, and the other the rhombohedral $R 3 c$ perovskite-type (or $\mathrm{LiNbO}_{3}$-type) phase obtained by heating the $P c$ phase in ambient pressure. The former is the first example of a simple $A B \mathrm{O}_{3}$ perovskite crystallizing in monoclinic $P c$ symmetry with $a \approx \sqrt{2} a_{\mathrm{pc}}, b \approx \sqrt{2} a_{\mathrm{pc}}$, and $c \approx$ $2 a_{\mathrm{pc}}$ unit cell. It also represents a rare example of "noncollinear ferrielectric" dipole order. Here, it should be noted that, in contrast to the $P C$ phases, the highersymmetry $R 3 c$ phases have been often observed in $\mathrm{ABO}_{3}$ compounds by the use of high-temperature and highpressure conditions; examples include $\mathrm{CuTaO}_{3},{ }^{32} A \mathrm{FeO}_{3}(A=$ $\mathrm{Sc}^{62} \mathrm{Ga}^{63}$ and $\left.\mathrm{In}^{64}\right), A_{\mathrm{TiO}}\left(A=\mathrm{Mg},{ }^{65} \mathrm{Mn},{ }^{66,67} \mathrm{Fe},{ }^{65,}{ }^{68} \mathrm{Zn},{ }^{69}\right.$ and $\left.\mathrm{Hg}^{70,71}\right), A \mathrm{GeO}_{3}\left(A=\mathrm{Mg}^{72,73} \mathrm{Fe}^{74}\right.$ and $\left.\mathrm{Zn}^{73}\right), A \mathrm{SnO}_{3}(A=$ $\mathrm{Mn}^{68}$ and $\left.\mathrm{Zn}^{74}\right), \mathrm{Li} B \mathrm{O}_{3}\left(B=\mathrm{Sb}^{76} \mathrm{~W},{ }^{77}\right.$ and $\left.\mathrm{Os}^{59}\right), \mathrm{Pb}-$ and $\mathrm{Bi}-$ containing perovskites ${ }^{78-83}$, and cation mixed perovskites. ${ }^{83-88}$ To examine the stable structure of HP$\mathrm{CuNbO}_{3}$, we subsequently performed phonon calculations using the polar $R 3 c$ phase as the parent structure. The crystal structure was optimized in the $R 3 c$ symmetry. Phonon dispersion curves for the $R 3 c$ structure are shown in Figure 10. We see an imaginary mode at the $F$ point of the Brillouin zone. Within the framework of a second-order phase transition, freezing of the F-point softmode yields a monoclinic polar $P c$ structure with $a \approx \sqrt{2}_{a_{\mathrm{pc}}}, b \approx \sqrt{2}_{a_{\mathrm{pc}}, c \approx}$ $2 a_{\mathrm{pc}}$ and $\beta \approx 95^{\circ}$, leading to the antiparallel off-center displacements of $\mathrm{Nb}^{5+}$ and the $a^{-} a^{-} c^{-}$-type tilts of $\mathrm{NbO}_{6}$ octahedra. Our calculations demonstrate that the $P c$ structure has a lower energy than the $R 3 c$ structure and is dynamically stable, consistent with the experimental observation that the low-temperature and hightemperature phases of $\mathrm{HP}-\mathrm{CuNbO}_{3}$ crystallize in the space groups $P C$ and $R 3 c$, respectively.

It is worth emphasizing that $\mathrm{HP}-\mathrm{CuNbO}_{3}(P c)$ has a lowersymmetry structure than $\mathrm{LiNbO}_{3}(R 3 c)$, despite the very close $t$ values between $\mathrm{CuNbO}_{3}(t=0.89)$ and $\mathrm{LiNbO}_{3}(t=$ 0.85). Comparing the crystal structure of $\mathrm{CuNbO}_{3}$ and $\mathrm{LiNbO}_{3}$ (see Figure 11) reveals that $A$-site cations $\left(\mathrm{Cu}^{+}\right.$in

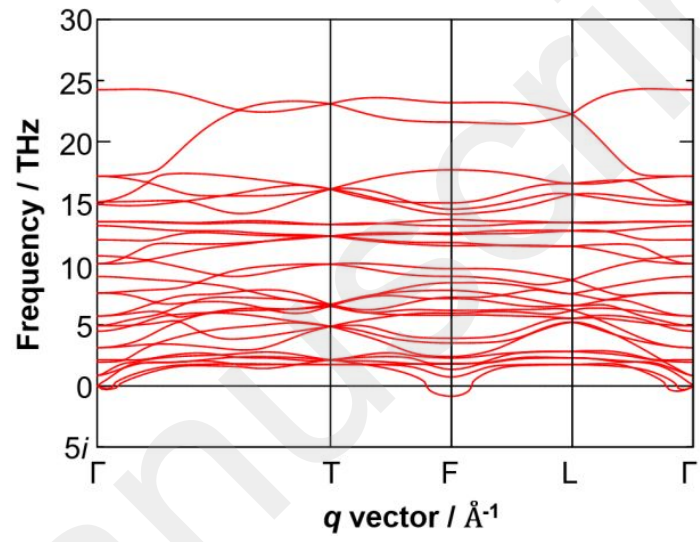

Figure 10. Phonon dispersion curves of $\mathrm{HP}-\mathrm{CuNbO}_{3}$ calculated with the $R 3 c$ symmetry.

(a) $\mathrm{Cu}$ in $\mathrm{PcCuNbO}_{3}$

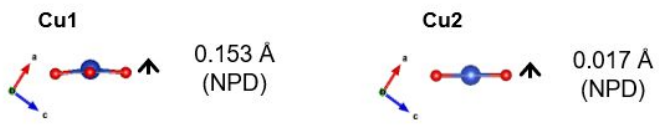

(b) $\mathrm{Li}$ in $\mathrm{R} 3 \mathrm{C} \mathrm{LiNbO}_{3}$

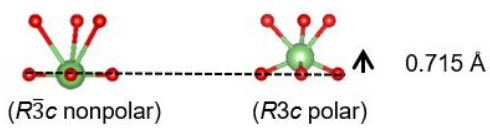

Figure 11. Short distance coordination around (a) $\mathrm{Cu}$ in HP$\mathrm{CuNbO}_{3}$ (this work) and (b) $\mathrm{Li}$ in $\mathrm{LiNbO}_{3}$ (from Ref. 21). The light green, blue, and red spheres correspond to $\mathrm{Li}, \mathrm{Cu}$, and $\mathrm{O}$ atoms, respectively.

$\mathrm{CuNbO}_{3}$ and $\mathrm{Li}^{+}$in $\mathrm{LiNbO}_{3}$ ) are displaced from the closedpacked oxygen planes along $[111]_{\mathrm{pc}}$, but the $\mathrm{Li}$ displacements are much larger than the $\mathrm{Cu}$ displacements. While the $\mathrm{Li}$ displacements in $R 3 C \mathrm{LiNbO}_{3}$ lead to the formation of $\mathrm{LiO}_{6}$ octahedra (see Figure 11b), the relatively 

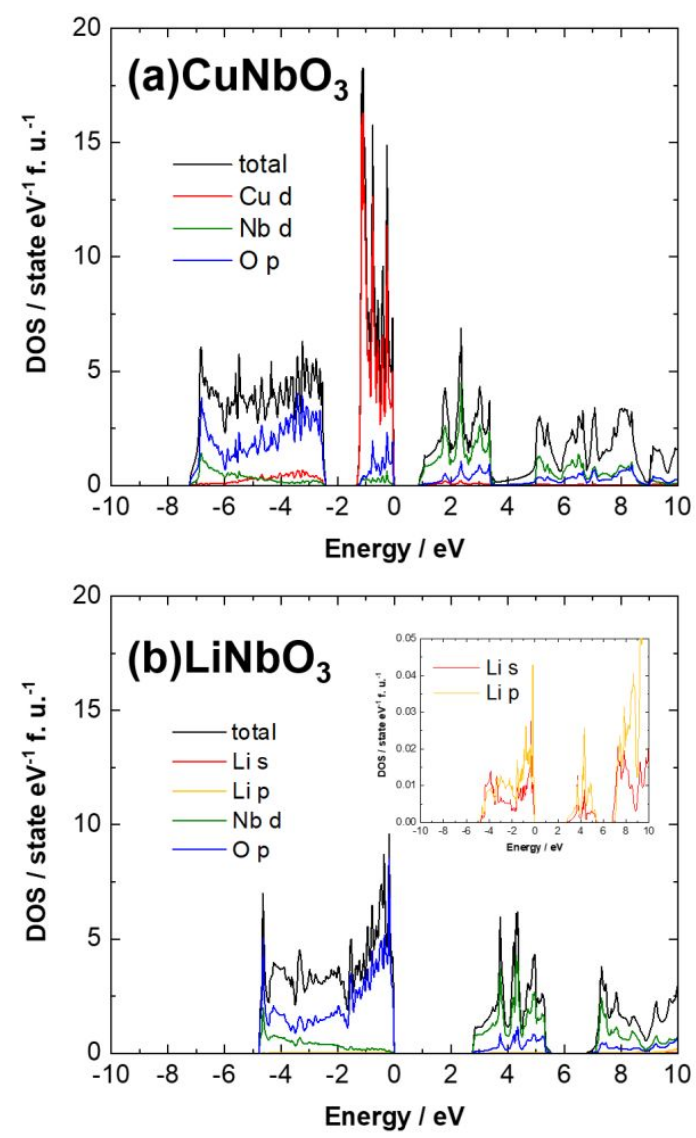

Figure 12. The calculated projected total and partial density of states (DOS) of $R 3 c$ (a) $\mathrm{CuNbO}_{3}$ and (b) $\mathrm{LiNbO}_{3}$. The zero of energy is set to the top of the valence band. The inset of (b) shows an enlarged view of the partial DOS of Li $4 \mathrm{~s}$ and Li $4 p$ states.

small $\mathrm{Cu}$ displacements in $\mathrm{HP}-\mathrm{CuNbO}_{3}$ confine the $\mathrm{Cu}-\mathrm{O}$ bonds to three oxide ions forming triangles (see Figure 11a), i.e., $\mathrm{Cu}^{+}$ions are virtually three-coordinated in HP$\mathrm{CuNbO}_{3}$. This may be explained by the difference in the bonding character between $\mathrm{Li}-\mathrm{O}$ (ionic) and $\mathrm{Cu}-\mathrm{O}$ (covalent).

To evaluate comparatively the bonding character for HP$\mathrm{CuNbO}_{3}$ and $\mathrm{LiNbO}_{3}$, we also calculated their electronic structures. In the calculations, we utilized the same $R 3 c$ structure as that used in the phonon calculations. Figure 12a, b depicts the calculated total and partial density of states (DOS) for $R 3 c \mathrm{CuNbO}_{3}$ and $\mathrm{LiNbO}_{3}$, respectively. For $\mathrm{CuNbO}_{3}$, the valence band mainly consists of $\mathrm{Cu} 3 \mathrm{~d}$ and $\mathrm{O} 2 \mathrm{p}$ states, and the conduction band is composed of the $\mathrm{Nb} 4 \mathrm{~d}$ state. The $\mathrm{Cu} 3 \mathrm{~d}$ state contributes to the formation of the top of valence band through the orbital overlap with the $02 p$ state (see Figure 12a). This is in striking contrast to $\mathrm{LiNbO}_{3}$, where the valence band is composed of the $02 p$ state, without any significant participation of Li orbitals (see Figure 12b). Thus, the covalent bond character of $A$-site cations is obvious for $\mathrm{CuNbO}_{3}$. Note that the $\mathrm{Nb} 4 \mathrm{~d}$ states of
$\mathrm{CuNbO}_{3}$ and $\mathrm{LiNbO}_{3}$, which are completely empty in the ionic limits, are slightly occupied through orbital overlap with the $02 p$ states, forming the bottom of the valence band. This is indicative of the $\mathrm{Nb}-\mathrm{O}$ covalency that drives the second-order Jahn-Teller effect. We believe that the covalent character of $\mathrm{Cu}-\mathrm{O}$ and $\mathrm{Nb}-\mathrm{O}$ bonds will be associated with the appearance of the noncollinear ferrielectric cation displacements as observed for HP$\mathrm{CuNbO}_{3}$.

\section{CONCLUSION}

A novel perovskite-type oxide, $\mathrm{CuNbO}_{3}$, has been synthesized at $12 \mathrm{GPa}$ and $1273 \mathrm{~K}$. It forms a monoclinic Pc structure at $300 \mathrm{~K}$, representing a rare example of a "noncollinear ferrielectric" dipole order. The $P c$ phase transforms to a "collinear ferroelectric" $R 3 c$ structure upon heating at $470 \mathrm{~K}$. The noncollinear ferrielectric $(P c)$ collinear ferroelectric $(R 3 c)$ transition is of displacive origin, and the condensing soft mode responsible for the phase transition is observed at the $\mathrm{F}$ point of the rhombohedral Brillouin zone, which corresponds to the structural distortion mainly due to the antiparallel off-center $\mathrm{Nb}$ displacements and the $a^{-} a^{-} c^{-} \mathrm{NbO}_{6}$ octahedral tilting. The original distortion within the monoclinic $P c$ perovskite phase, in particular with respect to $\mathrm{LiNbO}_{3}$, is explained on the basis of bonding character, as highlighted by electronic structure calculations.

\section{ASSOCIATED CONTENT}

\section{Supporting Information}

The Supporting Information is available free of charge on the ACS Publications website at DOI: XXXX.

Dependence of sample quality on synthesis pressures, oscilloscope traces of the SHG signals, and detailed structural analysis results (selected bond lengths and angles, and lattice parameters at various temperatures).

\section{Accession Codes}

CCDC 1977808 contains the supplementary crystallographic data for this paper. These data can be obtained free of charge via www.ccdc.cam.ac.uk/data_request/cif, or by emailing data request@ccdc.cam.ac.uk, or by contacting The Cambridge Crystallographic Data Centre, 12 Union Road, Cambridge CB2 1EZ, UK; fax: +44 1223336033 .

\section{AUTHOR INFORMATION}

\section{Corresponding Author}

*Email for K.F.: fujita.koji.5w@kyoto-u.ac.jp

\section{Present Address}

${ }^{\dagger}$ (M.F.) Laboratory for Materials and Structures, Institute of Innovative Research, Tokyo Institute of Technology, Yokohama 226-8503, Japan

Author Contributions 
All authors have given approval to the final version of the manuscript.

\section{Funding Sources}

This work was financially supported by JSPS KAKENHI Grantin-Aids for Scientific Research (A) (Grant No. 17H01320) and (B) (Grant No. 19H02433), and Challenging Research (Exploratory) (Grant No. 18K18940). K. F. also thanks a grant from The Murata Science Foundation.

\section{ACKNOWLEDGEMENT}

SXRD experiments were performed on BL02B2 (Proposal Nos. 2019A1071 and 2019B1384) at SPring-8 with the approval of JASRI. XANES experiments were carried out on BL14B2 (Proposal Nos. 2017B1900 and 2019A1650). NPD experiments at $\mathrm{D} 2 \mathrm{~B}$ were supported by a beam time allocation from Institut Laue-Langevin (Proposal No. 5-23714); doi:10.5291/ILL-DATA.5-23-714). The authors thank Suguru Yoshida and Jinsuke Miyake for their help with the NPD measurements.

\section{REFERENCES}

1) Saito, Y.; Takao, H.; Tani, T.; Nonoyama, T.; Takatori, K.; Homma, T.; Nagaya, T.; Nakamura, M. Lead-free piezoceramics. Nature 2004, 432, 84-87.

2) Zuo, R.; Rödel, J.; Chen, R.; Li, L. Sintering and electrical properties of lead-free $\mathrm{Na}_{0.5} \mathrm{~K}_{0.5} \mathrm{NbO}_{3}$ piezoelectric ceramics. J. Am. Ceram. Soc. 2006, 89, 2010-2015.

3) Wu, J.; Xiao, D.; Zhu, J. Potassium-Sodium Niobate Lead-Free Piezoelectric Materials: Past, Present, and Future of Phase Boundaries. Chem. Rev. 2015, 115, 2559-2595.

4) Cohen, D.A.; Hossein-Zadeh, D.A.; Levi, A.F.J. High-Q microphotonic electro-optic modulator. Solid State Electron. 2001, 45, 1577-1589.

5) Liu, J. W.; Chen, G.; Li, Z. H.; Zhang, Z.G. Hydrothermal synthesis and photocatalytic properties of $\mathrm{ATaO}_{3}$ and $\mathrm{ANbO}_{3}(\mathrm{~A}=\mathrm{Na}$ and K). Int. J. Hydrogen Energy 2007, 32, 2269-2272.

6) Shi, H.; Zou, Z. Photophysical and photocatalytic properties of $\mathrm{ANbO}_{3}(\mathrm{~A}=\mathrm{Na}, \mathrm{K})$ photocatalysts. J. Phys. Chem. Solids 2012, 73, 788-792.

7) Huan, Y.; Shen, H.; Zhu, Y.; Li, M.; Li, H.; Wang, Z.; Hao, Y.; Wei, T. Enhanced ferro-photocatalytic performance for $\mathrm{ANbO}_{3} \mathrm{CA}=$ $\mathrm{Na}, \mathrm{K})$ nanoparticles. Math. Biosci. Eng. 2019, 16, 4122-4134.

8) Brese, N. E.; O'keeffe, M. Bond-Valence Parameters for Solids. Acta Cryst. 1991, B47, 192-197.

9) Shirane, G.; Danner, H.; Pavlovic, A.; Pepinsky, R. Phase Transitions in Ferroelectric $\mathrm{KNbO}_{3}$. Phys. Rev. 1954, 93, 672673.

10) Postnikov, A. V.; Neumann, T.; Borstel, G. Ferroelectric structure of $\mathrm{KNbO}_{3}$ and $\mathrm{KTaO}_{3}$ from first-principles calculations. Phys. Rev. B 1993, 48, 5910-5918.

11) Kawamura, S.; Magome, E.; Moriyoshi, C.; Kuroiwa, Y.; Taniguchi, N.; Tanaka, H.; Maki, S.; Takata, M.; Wada, S. Electronic Polarization in $\mathrm{KNbO}_{3}$ Visualized by Synchrotron Radiation Powder Diffraction. Jpn. J. Appl. Phys. 2013, 52, 09KF04.

12) Cohen, R. E. Origin of ferroelectricity in perovskite oxides. Nature 1992, 358, 136-138.

13) Kunz, M.; Brown, I. D. Out-of-Center Distortions around Octahedrally Coordinated $d^{0}$ Transition Metals. J. Solid State Chem. 1995, 115, 395-406.

14) Ok, K. M.; Halasyamani, P. S.; Casanova, D.; Llunell, M.; Alemany, P.; Alvarez, S. Distortions in Octahedrally
Coordinated $\mathrm{d}^{0}$ Transition Metal Oxides: A Continuous Symmetry Measures Approach. Chem. Mater. 2006, 18, 31763183.

15) Abrahams, S. C.; Reddy, J. M.; Bernstein, J. L. Ferroelectric Lithium Niobate. 3. Single Crystal X-Ray Diffraction study at $24^{\circ}$ C. J. Phys. Chem. Solids 1966, 27, 997-1012.

16) Weis, R. S.; Gaylord, T. K. Lithium Niobate: Summary of Physical Properties and Crystal Structure. Appl. Phys. A. 1985, 37, 191-203.

17) A. M. Glazer, The Classification of Tilted Octahedra in Perovskites. Acta Cryst. 1972, B28, 3384-3392

18) Sakowski-Cowley, A. C.; Łukaszewicz, K.; Megaw, H. D. The Structure of Sodium Niobate at Room Temperature, and the Problem of Reliability in Pseudosymmetric Structures. Acta Cryst. 1969, B25, 851-865.

19) Megaw, H. D. The seven phases of sodium niobite. Ferroelectrics 1974, 7, 87-89.

20) Mishra, S. K.; Choudhury, N.; Chaplot, S. L.; Krishna, P. S. R.; Mittal, R. Competing antiferroelectric interaction in $\mathrm{NaNbO}_{3}$ : Neutron diffraction and theoretical studies. Phys. Rev. B 2007, 76, 024110.

21) Koruza, J.; Tellier, J.; Malič, B.; Bobnar, V.; Kosec, M. Phase transitions of sodium niobate powder and ceramics, prepared by solid state synthesis. J. Appl. Phys. 2010, 108, 113509.

22) Johnston, K. E.; Tang, C. C.; Parker, J. E.; Knight, K. S.; Lightfoot, P.; Ashbrook, S. E. The Polar Phase of $\mathrm{NaNbO}_{3}$ : A Combined Study by Powder Diffraction, Solid-State NMR, and FirstPrinciples Calculations. J. Am. Chem. Soc. 2010, 132, 87328746.

23) Fábry, J.; Zikmund, Z.; Kania, A.; Petříček, V. Silver niobium trioxide, $\mathrm{AgNbO}_{3}$. Acta Cryst. 2000, C56, 916-918.

24) Sciau, P.; Kania, A.; Dkhil, B.; Suard, E.; Ratuszna, A. Structural investigation of $\mathrm{AgNbO}_{3}$ phases using x-ray and neutron diffraction. J. Phys.: Condens. Matter 2004, 16, 2795-2810.

25) Fu, D.; Endo, M.; Taniguchi, H.; Taniyama, T.; Itoh, Mitsuru. $\mathrm{AgNbO}_{3}$ : A lead-free material with large polarization and electromechanical response. Appl. Phys. Lett. 2007, 90, 252907.

26) Yashihma, M.; Matsuyama, S.; Sano, R.; Itoh, M.; Tsuda, K.; Fu, D. Structure of Ferroelectric Silver Niobate $\mathrm{AgNbO}_{3}$. Chem. Mater. 2011, 23, 1643-1645.

27) Yashima, M.; Matsuyama, S. Origin of the Ferrielectricty and Visible-Light Photocatalytic Activity of Silver Niobate $\mathrm{AgNbO}_{3}$. J. Phy. Chem. C 2012, 116, 24902-24906.

28) Joshi, U. A.; Palasyuk A. M.; Maggard, P. A. Photoelectrochemical Investigation and Electronic Structure of a p-Type $\mathrm{CuNbO}_{3}$ Photocathode. J. Phys. Chem. C. 2011, 115, 13534-13539.

29) Harb, M.; Masih, D.; Takanabe, K. Screened coulomb hybrid DFT investigation of band gap and optical absorption predictions of $\mathrm{CuVO}_{3}, \mathrm{CuNbO}_{3}$ and $\mathrm{Cu}_{5} \mathrm{Ta}_{11} \mathrm{O}_{30}$ materials. Phys. Chem. Chem. Phys. 2014, 16, 18198-18204.

30) Pralong, V.; Reddy, M. A,; Caignaert, V.; Malo, S.; Lebedev, O. I.; Varadaraju, U. V.; Raveau, B. A New Form of $\mathrm{LiNbO}_{3}$ with a Lamellar Structure Showing Reversible Lithium Intercalation. Chem. Mater. 2011, 23, 1915-1922.

31) Rodgers, J. A.; Williams, A. J.; Attfield, J. P. High-pressure / High-temperature Synthesis of Transition Metal Oxide Perovskites. Z. Naturforsch. B, 2014, 61, 1515-1526.

32) Belik, A. A.; and Yi, W. High-pressure synthesis, crystal chemistry and physics of perovskites with small cations at the A site. J. Phys.: Condens. Matter 2014, 26, 163201.

33) Sleight, A. W.; Prewitt, C. T. Preparation of $\mathrm{CuNbO}_{3}$ and $\mathrm{CuTaO}_{3}$ at high pressure. Mater. Res. Bull. 1970, 5, 207-212.

34) Rodríguez-Carvajal, J. Recent advances in magnetic structure determination by neutron powder diffraction. Physica 1993 B192, 55-69. 
35) Petříček, V.; Dušek, M.; Palatinus, L. Crystallographic Computing System JANA2006: General features. Z. Kristallogr. 2014, 229, 345-352.

36) Louër, D.; Boultif, A. Powder pattern indexing and the dichotomy algorithm. Z. Kristallogr. Suppl. 2007, 26, 191-196.

37) Altomare, A.; Cuocci, C.; Giacovazzo, C.; Moliterni, A.; Rizzi, R.; Corriero, N.; Falcicchio, A. EXPO2013: a kit of tools for phasing crystal structures from powder data. J. Appl. Cryst. 2013, 46, 1231-1235.

38) Izumi, F.; Momma, K. VESTA 3 for three-dimensional visualization of crystal, volumetric and morphology data. $J$. Appl. Cryst. 2011, 44, 1272-1276.

39) Blöchl, P. E. Projector augmented-wave method. Phys. Rev. B 1994, 50, 17953-17979.

40) Kresse, G.; Hafner, J. Ab intio molecular dynamics for openshell transition metals. Phys. Rev. B 1993, 48, 13115-13118.

41) Kresse, G.; Furthmüller, J. Efficient iterative schemes for $a b$ initio total-energy calculations using a plane-wave basis set. Phys. Rev. B 1996, 54, 11169-11186.

42) Kresse, G.; Joubert, D. From ultrasoft pseudopotentials to the projector augmented wave method. Phys. Rev. B 1999, 59, 1758-1775.

43) Monkhorst, H. J.; Pack, J. D. Special points for Brillouin-zone integrations. Phys. Rev. B 1976, 13, 5188-5192.

44) Perdew, J. P.; Ruzsinszky, A.; Csonka, G. I.; Vydrov, O. A.; Scuseria, G. E.; Constantin, L. A.; Zhou, X.; Burke, K. Restoring the Density-Gradient Expansion for Exchange in Solids and Surfaces. Phys. Rev. Lett. 2008, 100, 136406.

45) Dudarev, S. L.; Botton, G. A.; Savrasov, S. Y.; Humphreys, C. J.; Sutton, A. P. Electron-energy-loss spectra and the structural stability of nickel oxide: An LSDA+U study. Phys. Rev. B 1998 , 57, 1505-1509.

46) Togo, A.; Oba, F.; Tanaka, I. Transition pathway of $\mathrm{CO}_{2}$ crystals under high pressures. Phys. Rev. B 2008, 77, 184101.

47) Togo, A.; Oba, F.; Tanaka, I. First-principles calculations of the ferroelastic transition between rutile-type and $\mathrm{CaCl}_{2}$-type $\mathrm{SiO}_{2}$ at high pressures. Phys. Rev. B 2008, 78, 134106.

48) Togo, A.; Tanaka, I. Evolution of crystal structures in metallic elements. Phys. Rev. B, 2013, 87, 184104.

49) Akamatsu, H.; Fujita, K.; Kuge, T.; Gupta, A. S.; Togo, A.; Lei, S., Xue, F.; Stone G.; Rondinelli, J. M.; Chen, L. Q.; Tanaka, I.; Gopalan, V.; Tanaka, K. Inversion Symmetry Breaking by Oxygen Octahedral Rotations in the Ruddlesden-Popper $\mathrm{NaRTiO}_{4}$ Family. Phys. Rev. Lett. 2014, 112, 187602

50) Togo, A.; Tanaka, I. First principles phonon calculations in materials science. Scr. Mater. 2015, 108, 1-5.

51) Anisimov, V. I.; Solovyev, I. V.; Korotin, M. A.; Czyżyk, M. T.; Sawatzky, G. A. Density-functional theory and $\mathrm{NiO}$ photoemission spectra. Phys. Rev. B 1993, 48, 16929-16934.

52) Schwarz, K.; Blaha, P.; Madsen, G. K. H. Electronic structure calculations of solids using the WIEN2k package for material sciences. Comput. Phys. Commun. 2002, 147, 71- 76.

53) Krause, M. O.; Oliver, J. H. Natural widths of atomic $K$ and $L$

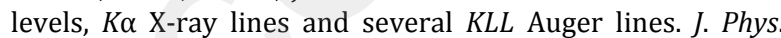
Chem. Ref. Data 1979, 8, 329-338.

54) Campbell, B. J.; Stokes, H. T.; Tanner, D. E.; Hatch, D. M. ISODISPLACE: a web-based tool for exploring structural distortions. J. Appl. Cryst. 2006, 39, 607-614.

55) Abrahams, S. C.; Marsh, P. Defect Structure Dependence on Composition in Lithium Niobate. Acta Cryst. 1986, B42, 61-68.

56) Iyi, N.; Kitamura, K.; Izumi, F.; Yamamoto, J. K.; Hayashi, T.; Asano, H.; Kimura, S. Comparative study of defect structures in lithium niobate with different compositions. J. Solid State Chem. 1992, 101, 340-352.

57) Salje, E. K. H.; Rehmann, S.; Pobell, F.; Morris, D.; Knight, K. S.; Herrmannsdörfer, T.; Dove, M. T. Crystal structure and paramagnetic behaviour of $\mathcal{\varepsilon}-\mathrm{WO}_{3-x}$.J. Phys.: Condens. Matter 1997, 9, 6563-6577.

58) Sugii, K.; Koizumi, H.; Miyazawa, S.; Kondo, S. Temperature variations of lattice parameters of $\mathrm{LiNbO}_{3}, \mathrm{LiTaO}_{3}$ and $\mathrm{Li}\left(\mathrm{Nb}_{1-y} \mathrm{Ta}_{y}\right) \mathrm{O}_{3}$ solid-solutions. J. Cryst. Growth 1976, 33, 199202.

59) Shi, Y.; Guo, Y.; Wang, X.; Princep, A. J.; Khalyavin, D.; Manuel, P.; Michiue, Y.; Sato, A.; Tsuda, K.; Yu, S.; Arai, M.; Shirako, Y.; Akaogi, M.; Wang, N.; Yamaura, K.; Boothroyd, A. T. A ferroelectric-like structural transition in a metal. Nat. Mater. 2013, 12, 1024-1027.

60) Propach, Von V. Kristallstruktur von $\mathrm{Ca}_{0.5} \mathrm{Cu}_{1.5} \mathrm{Ti}_{2} \mathrm{O}_{6}$, $\mathrm{Cu}_{1.5} \mathrm{TaTiO}_{6}$ und $\mathrm{CuTa}_{2} \mathrm{O}_{6}$. Das spektroskopische Verhalten von $\mathrm{Cu}^{2+}$-lonen in kuboktaedrischer Umgebung. Z. anorg. allg. Chem. 1977, 435, 161-171.

61) Ebbinghaus, S. G. Influence of composition and thermal treatment on the properties of $\mathrm{Cu}_{2+x} \mathrm{Ta}_{4} \mathrm{O}_{12+\delta}$ Prog. Solid State Chem. 2007, 35, 421-431.

62) Kawamoto, T.; Fujita, K.; Yamada, I.; Matoba, T.; Kim, S. J.; Gao, P.; Pan, X.; Findlay, S. D.; Tassel, C.; Kageyama, H.; Studer, A. J.; Hester, J.; Irifune, T.; Akamatsu, H.; Tanaka, K. Roomtemperature polar ferromagnet $\mathrm{ScFeO}_{3}$ transformed from a high-pressure orthorhombic perovskite phase. J. Am. Chem. Soc. 2014, 136, 15291-15299.

63) Niu, H.; Pitcher, A. J.; Corkett, A. J.; Ling, S.; Mandal, P.; Zanella, M.; Dawson, K.; Stamenov, P.; Batuk, D.; Abakumov, A. M.; Bull, C. L.; Smith, R. I.; Murray, C. A.; Day, S. J.; Slater, B.; Cora, F.; Claridge, J. B.; Rosseinsky, M. J. Room Temperature Magnetically Ordered Polar Corundum $\mathrm{GaFeO}_{3}$ Displaying Magnetoelectric Coupling. J. Am. Chem. Soc. 2017, 139, 15201531.

64) Fujita, K.; Kawamoto, T.; Yamada, I.; Hernandez, O.; Hayashi, N.; Akamatsu, H.; Lafargue-Dit-Hauret, W.; Rocquefelte, X.; Fukuzumi, M.; Manuel, P.; Studer, A. J.; Knee, C. S.; Tanaka, K $\mathrm{LiNbO}_{3}$-type InFeO3: Room-temperature polar magnet without second-order Jahn-Teller active ions. Chem. Mater. 2016, 28, 6644-6655.

65) Linton, J. A.; Fei, Y.; Navrotsky, A. Complete Fe-Mg solid solution in lithium niobate and perovskite structures in titanates at high pressures and temperatures. Am. Mineral. 1997, 82, 639-642.

66) Ko, J.; and Prewitt, C. T. High-pressure phase transition in $\mathrm{MnTiO}_{3}$ from the ilmenite to the LiNbO3 structure. Phys. Chem. Miner. 1988, 15, 355-362.

67) Aimi, A.; Katsumata, T.; Mori, D.; Fu, D.; Itoh, M.; Kyomen, T.; Hiraki, K.; Takahashi, T.; Inaguma, Y. High-Pressure Synthesis and Correlation between Structure, Magnetic, and Dielectric Properties in $\mathrm{LiNbO}_{3}$-Type $\mathrm{MnMO}_{3}(\mathrm{M}=\mathrm{Ti}, \mathrm{Sn})$. Inorg. Chem. 2011, 50, 6392-6398.

68) Leinenweber, K.; Utsumi, W.; Tsuchida, Y.; Yagi, T.; Kurita, K. Unquenchable High-Pressure Perovskite Polymorphs of $\mathrm{MnSnO}_{3}$ and $\mathrm{FeTiO}_{3}$. Phys. Chem. Miner. 1991, 18, 244-250.

69) Inaguma, Y.; Aimi, A.; Shirako, Y.; Sakurai, D.; Mori, D.; Kojitani, H.; Akaogi, M.; Nakayama, M. High-pressure synthesis, crystal structure, and phase stability relations of a $\mathrm{LiNbO}_{3}$-type polar titanate $\mathrm{ZnTiO}_{3}$ and its reinforced polarity by the secondorder Jahn-Teller effect. J. Am. Chem. Soc. 2014, 136, 27482756.

70) Sleight, A. W.; Prewitt, C. T. High-Pressure $\mathrm{HgTiO}_{3}$ and $\mathrm{HgPbO}_{3}$ : Preparation, Characterization, and Structure. J. Solid State Chem. 1973, 6, 509-512.

71) Shan,Y. J.; Inaguma, Y.; Tetsuka, H.; Nakamura, T.; Gauckler, L. J. Synthesis and Phase Transition of $\mathrm{HgTiO}_{3}$. Ferroelectrics 2006, 337, 71-76.

72) Leinenweber, K.; Wang, Y.; Yagi, T.; Yusa, H. An unquenchable perovskite phase of $\mathrm{MgGeO}_{3}$ and comparison with $\mathrm{MgSiO}_{3}$ perovskite. Am. Mineral. 1994, 79, 197-199. 
73) Akaogi, M.; Kojitani, H.; Yusa, H.; Yamamoto, R.; Kido, M.; Koyama, K. High-pressure transitions and thermochemistry of $\mathrm{MGeO}_{3}(\mathrm{M}=\mathrm{Mg}, \mathrm{Zn}$ and $\mathrm{Sr})$ and $\mathrm{Sr}$-silicates: systematics in enthalpies of formation of $\mathrm{A}^{2+} \mathrm{B}^{4+} \mathrm{O}_{3}$ perovskites. Phys. Chem. Miner. 2005, 32, 603-613.

74) Hattori, T.; Matsuda, T.; Tsuchiya, T.; Nagai, T.; Yamanaka, T. Clinopyroxene-perovskite phase transition of $\mathrm{FeGeO}_{3}$ under high pressure and room temperature. Phys. Chem. Miner. 1999, 26, 212-216.

75) Inaguma, Y.; Yoshida, M.; Katsumata, T. A polar oxide $\mathrm{ZnSnO}_{3}$ with a LiNbO3-type structure. J. Am. Chem. Soc. 2008, 130, 6704-6705.

76) Inaguma, Y.; Aimi, A.; Mori, D.; Katsumata, T.; Ohtake, M.; Nakayama, M.; Yonemura, M.High-Pressure Synthesis, Crystal Structure, Chemical Bonding, and Ferroelectricity of $\mathrm{LiNbO}_{3}$ Type LiSbO3. Inorg. Chem. 2018, 57, 15462-15473.

77) Ishida,K.; Ikeuchi, Y.; Tassel, C.; Takatsu, H.; Brown, C. M.; Kageyama, H High-Pressure Synthesis of Non-Stoichiometric $\mathrm{Li}_{x} \mathrm{WO}_{3}(0.5 \leq x \leq 1.0)$ with $\mathrm{LiNbO}_{3}$ Structure. Inorganics 2019, $7,63$.

78) Belik, A. A.; Wuernisha, T.; Kamiyama, T.; Mori, K.; Maie, M.; Nagai, T.; Matsui, Y.; Takayama-Muromachi, E. High-Pressure Synthesis, Crystal Structures, and Properties of Perovskitelike $\mathrm{BiAlO}_{3}$ and Pyroxene-like $\mathrm{BiGaO}_{3}$. Chem. Mater. 2006, 18, 133-139.

79) Inaguma, Y.; Yoshida, M.; Tsuchiya, T.; Aimi, A.; Tanaka, K.; Katsumata, T.; Mori, D. High-pressure synthesis of novel lithium niobate type oxides. J. Phys.: Conf. Ser. 2010, 215, 012131.

80) Inaguma, Y.; Tanaka, K.; Tsuchiya, T.; Mori, D.; Katsumata, T.; Ohba, T.; Hiraki, K.; Takahashi, T.; Saitoh, H. Synthesis, Structural Transformation, Thermal Stability, Valence State, and Magnetic and Electronic Properties of $\mathrm{PbNiO}_{3}$ with Perovskite and $\mathrm{LiNbO}_{3}$-Type Structures. J. Am. Chem. Soc. 2011, 133, 16920-16929.

81) Yu, R.; Hojo, H.; Mizoguchi, T.; Azuma, M. A new LiNbO3-type polar oxide with closed-shell cations: $\mathrm{ZnPbO}_{3}$. J. Appl. Phys. 2015, 118, 094103.

82) Mori, D.; Tanaka, K.; Saitoh, H.; Kikegawa, T.; Inaguma, Y. Synthesis, Direct Formation under High Pressure, Structure, and Electronic Properties of $\mathrm{LiNbO}_{3}$-type Oxide $\mathrm{PbZnO}_{3}$. Inorg. Chem. 2015, 54, 11405-11410.

83) Sakai, Y.; Nishikubo, T.; Ogata, T.; Ishizaki, H.; Imai, T.; Mizumaki, M.; Mizokawa, T.; Machida, A.; Watanuki, T.; Yokoyama, K.; Okimoto, Y.; Koshihara, S.; Das, H.; Azuma, M. Polar-Nonpolar Phase Transition Accompanied by Negative Thermal Expansion in Perovskite-Type $\mathrm{Bi}_{1-x} \mathrm{~Pb}_{x} \mathrm{NiO}_{3}$. Chem. Mater. 2019, 31, 4748-4758.

84) Belik, A. A.; Furubayashi, T.; Yusa, H.; Takayama-Muromachi, E. Perovskite, $\mathrm{LiNbO}_{3}$, Corundum, and Hexagonal Polymorphs of $\left(\operatorname{In}_{1-x} \mathrm{M}_{x}\right) \mathrm{MO}_{3}$. J. Am. Chem. Soc. 2011, 133, 9405-9412.

85) Belik, A. A.; Yi, W.; Kumagai, Y.; Katsuya, Y.; Tanaka, M.; Oba, F. $\mathrm{LiNbO}_{3}$-Type Oxide $\left(\mathrm{Tl}_{1-x} \mathrm{Sc}_{x}\right) \mathrm{ScO}_{3}$ : High-Pressure Synthesis, Crystal Structure, and Electronic Properties. Inorg. Chem. 2016, 55, 1940-1945.

86) Li, M. R.; Walker, D.; Retuerto, M.; Sarkar, T.; Hadermann, J.; Stephens, P. W.; Croft, M.; Ignatov, A.; Grams, C. P.; Hemberger, J.; Nowik, I.; Halasyamani, P. S.; Tran, T. T.; Mukherjee, S.; Dasgupta, T. S.; Greenblatt, M. Polar and magnetic $\mathrm{Mn}_{2} \mathrm{FeMO}_{6}$ $(\mathrm{M}=\mathrm{Nb}, \mathrm{Ta})$ with $\mathrm{LiNbO}_{3}$-type structure: High-pressure synthesis. Angew. Chem. Int. Ed. 2013, 52, 8406-8410.

87) Li, M. R.; Stephens, P. W.; Retuerto, M.; Sarkar, T.; Grams, C. P.; Hemberger, J.; Croft, M. C.; Walker, D.; Greenblatt, M. Designing Polar and Magnetic Oxides: $\mathrm{Zn}_{2} \mathrm{FeTaO}_{6}$ - in Search of Multiferroics. J. Am. Chem. Soc. 2014, 136, 8508-8511.

88) Han, Y.; Zeng, Y.; Hendrickx, M.; Hadermann, J.; Stephens, P. W.; Zhu, C.; Grams, C. P.; Hemberger, J.; Frank, C.; Li, S.; Wu, M.;
Retuerto, M.; Croft, M.; Walker, D.; Yao, D. X.; Greenblatt, M.; Li, M. R. Universal A-Cation Splitting in LiNb03-Type Structure Driven by Intrapositional Multivalent Coupling. J. Am. Chem. Soc. 2020, 142, 7168-7178. 


\section{For Table of Contents Only}
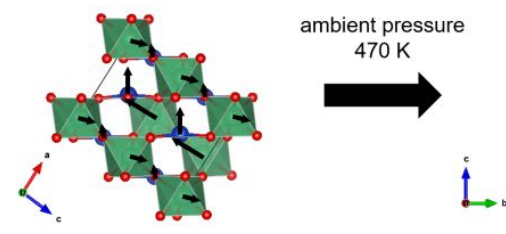

Rhombohedral $R 3 c$

\section{Noncollinear Ferrielectric Collinear Ferroelectric}

Synopsis: Perovskite-type $\mathrm{CuNbO}_{3}$ was synthesized at 12 $\mathrm{GPa}$ and $1473 \mathrm{~K}$. It crystallizes in a polar monoclinic $P c$ space group. This $P c$ phase exhibits unusual noncollinear ferrielectric structure, due to parallel $\mathrm{Cu}$ displacements and antiparallel $\mathrm{Nb}$ displacements along different axes, representing a new type of polar phase in the perovskite structure. At about $470 \mathrm{~K}$, it transforms into the collinear ferroelectric $R 3 c$ structure that features parallel $\mathrm{Cu}$ and $\mathrm{Nb}$ displacements in the same direction. 